\title{
基于天然小分子化合物的超分子自组装
}

\author{
高玉霞 ${ }^{a}$ 胡君 ${ }^{b}$ 巨勇*,a \\ ( ${ }^{a}$ 清华大学化学系 生命有机磷化学及化学生物学教育部重点实验室 北京 100084) \\ $\left({ }^{b}\right.$ 中国科学院长春应用化学研究所 高分子物理与化学国家重点实验室 长春 130022)
}

\begin{abstract}
摘要 天然产物来源广泛、手性结构独特、具有多修饰位点、良好的生物相容性和可控的降解性, 与其他非天然产物 的自组装体系相比，具有更多的优势. 简单修饰的天然产物在溶剂中容易形成氢键、 $\pi-\pi$ 堆积、范德华作用等非共价键 作用，促使分子有序排列形成聚集体，成为超分子自组装体系的重要构筑基元. 同时，其独特的手性结构在分子有序 排列过程中, 通常会实现手性由分子层次到超分子层次的传递和放大, 因此, 可用于构建螺旋带、纳米管等多种手性组 装体. 天然产物良好的生物相容性和生物活性，也使得基于此类化合物的组装体可应用于组织工程、药物传递、细胞 成像等生命科学领域, 显示其广阔的应用前景. 本文介绍了基于氨基酸、糖、核苷碱基、甾体、三萜等天然产物缀合 物在超分子自组装特性方面的研究概况及其发展趋势.
\end{abstract}

关键词 天然小分子; 超分子自组装; 非共价键作用; 手性; 生物活性

\section{Supramolecular Self-Assembly Based on Natural Small Molecules}

$$
\text { Gao, Yuxia }{ }^{a} \quad \mathrm{Hu}, \mathrm{Jun}^{b} \quad \text { Ju, Yong }{ }^{*, a}
$$

( ${ }^{a}$ Key Laboratory of Bioorganic Phosphorus Chemistry \& Chemical Biology, Ministry of Education, Department of Chemistry, Tsinghua University, Beijing 100084)

( ${ }^{b}$ State Key Lab of Polymer Physics and Chemistry, Changchun Institute of Applied Chemistry, Chinese Academy of Sciences, Changchun 130022)

\begin{abstract}
Natural products have been widely used in the construction of supramolecular self-assemblies due to not only their abundant resources, unique chiral structures, and multiple reaction sites, but also the good biocompatibility and the controllable degradability. Through the simple chemical modification natural products-based functional molecules would self-assemble into various supramolecular assemblies primarily promoted by non-covalent interactions, such as hydrogen bonding, $\pi-\pi$ stacking, van der Waals forces, electrostatic interactions, and charge-transfer interactions. During the assembly process, their unique molecular chirality would be transferred and magnified into supramolecular assemblies, thus providing a facile method to fabricate helical ribbons, nanotubes, and other chiral nanostructures. Furthermore, their good biocompatibility and biological activity endow the assemblies with the ability to be widely applied in tissue engineering, drug delivery, cell imaging, and so on. In this review, recent developments of supramolecular self-assemblies based on amino acids, sugars, nucleosides, steroids, triterpenoids and other natural products were summarized.
\end{abstract}

Keywords natural small molecules; supramolecular self-assembly; non-covalent interactions; chirality; biological activity

\section{1 引言}

超分子自组装是超分子化学的一个重要分支, 它是 指分子在氢键、 $\pi-\pi$ 作用、范德华力、电荷转移作用、 偶极一偶极以及疏水作用等多种非共价键作用下，有序 排列形成聚集体的过程 ${ }^{[1 \sim 3]}$. 该组装过程是分子在溶剂 中的一种自发行为, 遵循能量最低原理, 其本质是分子 间的作用力, 因此, 可以在分子间形成非共价键作用力 的化合物通常可以产生自组装.

随着超分子化学的发展, 自组装已成为创造新物质
和新功能结构的一种手段, 分子在一定条件下可组装形 成凝胶、囊泡、胶束、纳米管、螺旋带等多种组装体 ${ }^{[4]}$, 应用于材料科学、生物医学、手性催化等多个领域 ${ }^{[5 \sim 9]}$. 许多分子都可用于超分子组装体的构建, 如 $\pi$-共轭体系 化合物、两亲性分子、金属有机配合物、脂肪酸衍生物、 氨基酸和糖类缀合物等 ${ }^{[10 \sim 12]}$. 其中, 天然产物因其来源 广泛、含量丰富、结构多样等诸多优势受到超分子化学 研究者的关注 ${ }^{[13,14]}$.

天然产物独特的手性结构和多作用位点, 决定了其 可作为构筑基元用于超分子组装体的构建 ${ }^{[15,16]}$. 同时,

\footnotetext{
*E-mail: juyong@tsinghua.edu.cn

Received January 8, 2016; published February 25, 2016.

Project supported by the National Natural Science Foundation of China (No. 21472108), the National Basic Research Program of China (973 Program, No. 2012CB821600), and Open Research Fund of State Key Laboratory of Polymer Physics and Chemistry, CIAC.

项目受国家自然科学基金(No. 21472108)、国家重大科学研究计划(973 计划, No. 2012CB821600)和高分子物理与化学国家重点实验室开放课题基金资 助.
} 
其良好的生物相容性和生物活性, 使得基于天然产物的 组装体可被应用于细胞培养、药物传递、红血球凝集抑 制、细菌吸附、细胞成像等生命科学领域 ${ }^{[17,18]}$.

本文结合我们课题组在三萜和甾体自组装性能方 面的研究工作，介绍了氨基酸、糖类、核苷碱基、甾体、 三萜、香豆素等天然产物在超分子体系构建及其自组装 特性方面的概况和发展趋势.

\section{2 基于天然小分子化合物的超分子自组装}

\section{1 氨基酸化合物的自组装}

氨基酸具有易修饰的氨基和羧基官能团, 容易通过 酰胺键将其连接起来得到不同序列的多肽结构. 分子间 形成的氢键可促使氨基酸单元有序排列形成组装体，而 且在自组装过程中氨基酸分子的手性通常会被放大, 得 到手性纳米材料 ${ }^{[19]}$.

在氨基酸骨架中引入芳香基团, 不仅可以改变分子 自身的两亲性, 还能在分子间产生 $\pi-\pi$ 堆积作用, 使其 与氢键、亲疏水作用共同驱动分子有序排列. 例如, 苯 基、荎基、萠基、芴甲氧羰酰基(Fmoc)等的引入会增强 分子的自组装能力, 使被芳香基团修饰的化合物 $1 \sim 6$ 在水中形成稳定的水凝胶 ${ }^{[20 ~ 22]}$.<smiles>O=C(/C=C/c1ccccc1)NC(Cc1ccccc1)C(=O)O</smiles><smiles>O=C(COc1ccc2ccccc2c1)NC(Cc1ccccc1)C(=O)O</smiles>

3<smiles>O=C(CCCc1ccc2ccc3cccc4ccc1c2c34)NC(Cc1ccccc1)C(=O)OCC1c2ccccc2-c2ccccc21</smiles>

Pandey 等 ${ }^{[23]}$ 发现苯环对位连接的酪氨酸二聚体 7 能在 $\mathrm{KOH} 、 \mathrm{Zn}^{2+}$ 同时存在的条件下形成凝胶. 当酪氨酸 的疏水片段苯酚基团被异丙基或苯基取代后，亮氨酸二 聚体 8 和苯丙氨酸二聚体 9 在上述条件下均只能形成沉 淀, 说明氨基酸结构的微小改变对成凝胶性质有较大的 影响. 通过对 7 形成凝胶的光谱性质进行研究, 发现 $\mathrm{Zn}^{2+}$ 与酪氨酸分子上的 $\mathrm{O} 、 \mathrm{~N}$ 形成配位作用, 协同苯酚 基团 $\pi-\pi$ 堆积作用以 $J$-聚集体形式排列, 形成螺旋纤维. 也间接证明了 8 和 9 不能形成凝胶的原因是缺少了 $\mathrm{Zn}^{2+}$ 与酚差基间的协同配位作用.<smiles>[Z]Cc1ccc(O)cc1C[C@H](NCc1ccc(CNC(Cc2ccc(O)cc2)C(=O)O)cc1)C(=O)O</smiles><smiles>CC(C)CC(CC(C)C)NCc1ccc(CN[C@@H](CC(=O)O)C(=O)O)cc1</smiles><smiles>O=C(O)C(Cc1ccccc1)NCc1ccc(CN[C@@H](Cc2ccccc2)C(=O)O)cc1</smiles>

二硫键是生物体内一种可逆的共价键，对蛋白质的 结构和功能具有重要作用. 胱氨酸是唯一含二硫键的天 然氨基酸, 研究其组装性质有助于更好地理解和模拟蛋 白质结构. 苯甲酰修饰的胱氨酸衍生物 10 是很好的凝 胶因子，其在水中形成的稳定凝胶，可用于喹啉类药物 分子的传递和释放 ${ }^{[24]}$.<smiles>O=C(NC(CSSC[C@H](NC(=O)c1ccccc1)C(=O)O)C(=O)O)c1ccccc1</smiles>

Sapala 等 ${ }^{[25]}$ 通过 “Click”反应，合成了大小不同的胱 氨酸环状分子 11 和 12 , 研究了它们在氯仿/甲醇混合溶 剂中的组装性质. 小环分子 11 可以自组装成螺旋管状 结构的凝胶，而大环分子 $\mathbf{1 2}$ 自组装形成囊泡，并利用二 硫键的还原响应特性实现了囊泡对染料的包裹和释放.
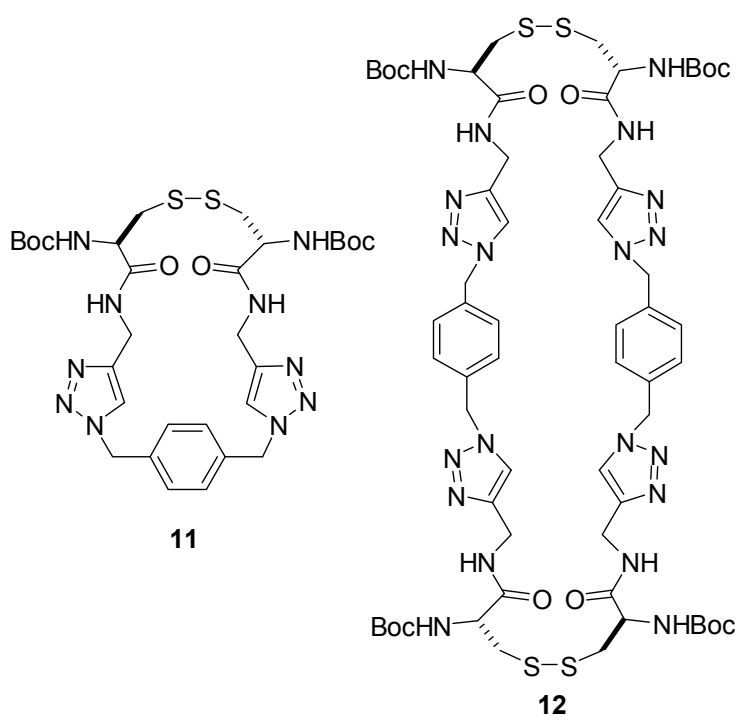

刘鸣华等 ${ }^{[26 ~ 29]}$ 系统地研究了谷氨酸及其衍生物的 组装性质，探讨了分子构型、金属离子、溶剂、光照等 因素对组装体形貌的影响，构建了多种不同尺寸的螺旋 纳米带、纳米管等手性材料. 他们发现长烷基链相连的 $L$-型谷氨酸二聚体 13 与三聚氰胺分子在水中相互作用 形成规整的纳米管结构, 且二者的比例决定了纳米管的 长度、直径以及壁厚，从而实现对组装体形貌的可控调 节. 组装体形貌不同是不同比例下氨基与羧基形成的氢 
键数目以及三聚氭胺分子间形成的 $\pi-\pi$ 堆积作用不等所 导致 ${ }^{[30]}$. 随后, 他们又发现分子 13 形成的外消旋体与 三聚氰胺混合可以得到新的螺旋组装体, 且对映体比 例、二聚体分子与三聚氧胺的比例都会影响组装体形 貌 $^{[31]}$.<smiles>Nc1nc(N)nc(N)n1</smiles>

最近, 他们发现吡啶盐修饰的谷氨酸两亲性分子 14 在乙醇、氯仿、丙酮等纯溶剂中均形成微观形貌为纤 维的沉淀(图 1a), 但加入少量水后, 沉淀转换成凝胶, 组装形貌变为各种管状、螺旋带状结构(图 1b 1d). 其 原因是水分子与嫝基形成的氢键促进分子有序排列, 同 时，烷基链的疏水效应和吡啶基团间的 $\pi-\pi$ 堆积也发挥 一定的作用 ${ }^{[32]}$. 在组装过程中, 谷氨酸分子的手性得到 了传递和放大，因此电镜下可观察到螺旋结构.
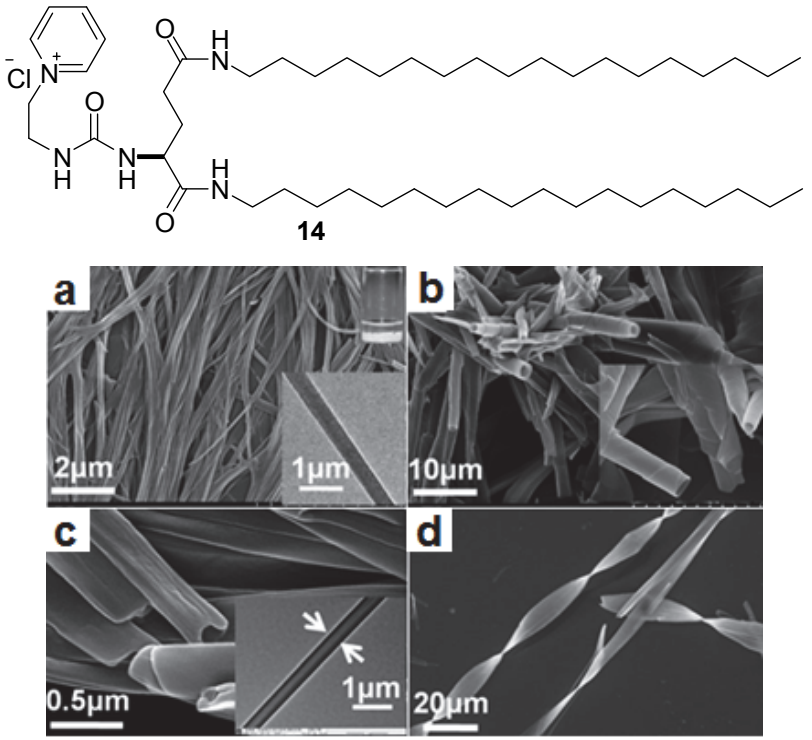

图 1 分子 14 在不同溶剂中形成的组装体形貌: (a)乙醇(沉淀), (b)氯 仿/水(凝胶), (c)丙酮/水(凝胶), (d) DMSO/水(凝胶), 内嵌图为相应的 透射电子显微镜(TEM)图

Figure 1 SEM images of the $\mathbf{1 4}$ precipitate in (a) ethanol, and xerogels in different organic- $\mathrm{H}_{2} \mathrm{O}$ solvents: (b) chloroform $/ \mathrm{H}_{2} \mathrm{O}$, (c) acetone $/ \mathrm{H}_{2} \mathrm{O}$, (d) $\mathrm{DMSO} / \mathrm{H}_{2} \mathrm{O}$, inset shows the corresponding TEM image ${ }^{[32]}$

赖氨酸也是常见的超分子构筑基元, 在其氨基和羧 基上引入疏水烷基链或芳香基团, 通常可以使分子在溶 剂中达到更好的亲疏水平衡, 形成有序组装体 ${ }^{[33 \sim 35]}$. Suzuki 等 ${ }^{[36]}$ 合成了一系列不同烷基修饰的赖氨酸衍生 物 15 21, 探究它们在不同有机溶剂中的凝胶性质. 烷 基链长度和酰胺键数目的差异使分子在溶剂中形成的 范德华作用力和氢键作用不同, 因而表现出不同的凝胶 性质. 其中, 化合物 19 的凝胶性质最好.<smiles>[R]C(=O)NCCCC[C@H](NC([R])=O)C([R2])=O</smiles>

$$
\begin{aligned}
& 15 \mathrm{R}^{1}=\mathrm{Me}, \mathrm{R}^{2}=\mathrm{R}^{3}=\mathrm{NHC}_{6} \mathrm{H}_{13} \\
& 16 \mathrm{R}^{1}=\mathrm{Me}, \mathrm{R}^{2}=\mathrm{R}^{3}=\mathrm{NHC}_{8} \mathrm{H}_{17} \\
& 17 \mathrm{R}^{1}=\mathrm{Me}, \mathrm{R}^{2}=\mathrm{R}^{3}=\mathrm{NHC}_{12} \mathrm{H}_{25} \\
& 18 R^{1}=E t, R^{2}=C_{11} H_{23}, R^{3}=N^{2} C_{6} H_{13} \\
& 19 \mathrm{R}^{1}=\mathrm{Et}, \mathrm{R}^{2}=\mathrm{C}_{11} \mathrm{H}_{23}, \mathrm{R}^{3}=\mathrm{NHC}_{12} \mathrm{H}_{25} \\
& 20 R^{1}=E t, R^{2}=C_{11} \mathrm{H}_{23}, R^{3}=N C_{18} H_{37} \\
& 21 R^{1}=E t, R^{2}=R^{3}=C_{11} H_{23}
\end{aligned}
$$

除了对单个氨基酸衍生物的组装性质进行研究外, 短肽类分子的组装行为也得到了研究者们的广泛关注. 其中最为突出的是源自 $\mathrm{A} \beta$ 淀粉样蛋白核心片段的苯丙 氨酸二肽分子 $22\left(\mathrm{NH}_{2}-\mathrm{Phe}-\mathrm{Phe}-\mathrm{CO}_{2} \mathrm{H}, \mathbf{F F}\right)$. 自 Gazit 等 ${ }^{[37]}$ 发现该分子可在水中自组装成稳定的纳米管后, 已有大量对该分子进行结构修饰、组装行为的调控和材 料应用的研究被报道 ${ }^{[38]}$.<smiles>N[C@@H](Cc1ccccc1)C(=O)NC(Cc1ccccc1)C(=O)O</smiles><smiles>NC(=O)C(Cc1ccccc1)NC(=O)[C@H](N)Cc1ccccc1</smiles>

李峻柏等 ${ }^{[39]}$ 研究了二肽分子 $22(\mathrm{FF})$ 及其衍生物的 组装性质和在材料方面的应用. 发现 22 除了可以在水 中形成规整的组装体以外，还可以在氯仿、甲苯等有机 溶剂中自组装成具有纤维网状结构的凝胶. 该凝胶可用 来包裹量子点和金纳米颗粒，制备新型的凝胶杂化复合 材料, 实现对无机粒子光学性质的稳定 ${ }^{[40]}$. 同时发现, 在生理条件下, 阳离子型二肽分子 $23\left(\mathrm{NH}_{2}-\mathrm{Phe}-\mathrm{Phe}-\right.$ $\mathrm{NH}_{2}$ ) 可在水中自组装形成纳米管. 在浓度稀释过程中, 纳米管逐渐变成囊泡, 而浓度增大之后囊泡再次变为纳 米管，实现了浓度对组装形貌的调控. 利用此特点, 将 负电荷的寡聚核苷酸通过静电作用吸附在正电荷的纳 米管上，当纳米管被稀释转化成囊泡时，核苷酸会吸附 在囊泡表面通过内吞作用进入细胞，从而实现了基因传

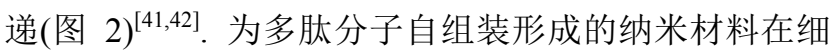
胞内药物释放、基因传递、组织工程等方面的应用提供 了思路.

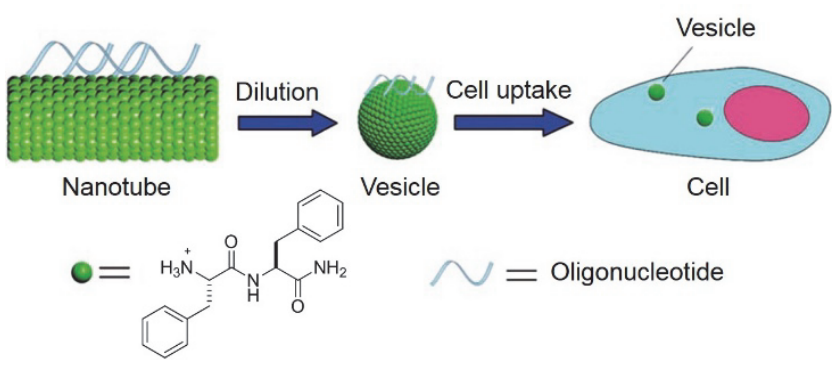

图 2 纳米管转化成囊泡实现葟聚核苷酸传递

Figure 2 Transition of the nanotubes into vesicles for oligonucleotide delivery ${ }^{[41]}$ 
在短肽分子上引入菜基、Fmoc 等芳香基团, 同样可 以增强分子间的 $\pi-\pi$ 作用力, 促使分子有序排列, 带来 较好的组装性质 ${ }^{[43]}$. Ulijn 小组 ${ }^{[4]}$ 发现不同 Fmoc 基团修 饰的二肽分子 24 30 可在水中形成稳定水凝胶, 但不 同二肽分子成凝胶的 $\mathrm{pH}$ 不相同. 值得注意的是, 分子 28 和 29 结构相似, 却表现出截然不同的组装行为. 28 可以形成凝胶, 而 29 只能结晶, 体现了氨基酸片段微小 差异对组装性质的影响. 在多个二肽分子中, 化合物 30 自组装形成的水凝胶稳定性最好, 其微观三维网络状结 构可用于软骨细胞的培养(图 3). 随后, 他们又发现 $\mathrm{pH}$ 能够很好地调控 30 形成水凝胶的形貌, 实现从纤维到 带状结构、最后到刚性片状过程的转变 ${ }^{[45]}$.

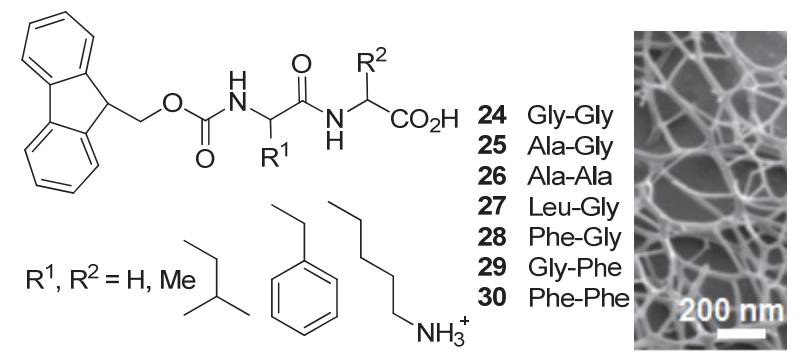

图 3 化合物 $\mathbf{2 4} \sim \mathbf{3 0}$ 结构以及 $\mathbf{3 0}$ 在水中形成凝胶形貌

Figure 3 Structures of compounds $\mathbf{2 4} \sim \mathbf{3 0}$ and SEM image of hydrogel formed by $\mathbf{3 0}^{[44]}$

$\mathrm{Xu}$ 等 ${ }^{[13,46 ~ 49]}$ 通过在苯丙二肽分子上引入菜基, 构 建了水凝胶因子 31 (NapFF), 之后, 再修饰上不同的生 物活性分子, 获得了多种类型的载药和酶促水凝胶. 当 31 上连接了可以吸附过渡金属 $\mathrm{UO}_{2}{ }^{2+}$ 的双磷酸盐基团 后, 化合物 32 形成的水凝胶可用来治愈被硝酸双氧铀 污染的小鼠细胞 ${ }^{[46]}$. 在磷酸酶的催化下, 连接酪氨酸磷 酸盐的前体分子 $33 \mathrm{a}$ 脱去磷酸基团得到凝胶因子 $33 \mathrm{~b}$, 在水中形成透明凝胶. 该酶促凝胶过程在大肠杆菌细胞 内也得到了实现 ${ }^{[47]}$. 化合物 34a 的水溶液加入磷酸酶去 磷酸化后转化成 $34 \mathrm{~b}$ 形成水凝胶, 该凝胶在三磷酸腺苷 ATP 存在条件下加入激酶后又会转化成 34a 的溶液, 在 温和条件下实现了凝胶-溶胶的可逆转变过程 ${ }^{[48]}$. 此外, 疏水药物分子紫杉醇也可以通过赖氨酸连接在 31 的侧 链上, 得到前体分子 $35 \mathrm{a}$, 在酶的催化作用下形成水凝 胶, 该酶促水凝胶体系可作为一种新型介质用于药物分 子的传递和释放 ${ }^{[49]}$.

杨志谋等 ${ }^{[50 ~ 53]}$ 利用酶解、二硫键还原、蛋白一肽相 互作用等生物方法制备了一系列基于短肽分子的水凝 胶, 应用于组织工程和药物传递领域. 他们通过合成二 硫键连接的水溶性短肽分子 36 , 利用二硫键的还原反 应，原位制备了水凝胶 37. 生物体内含有的谷胱甘肽 GSH, 也可以实现上述溶液到凝胶的转变过程 ${ }^{[54]}$.

由上可见，简单修饰的氨基酸类化合物在水、有机 溶剂中都表现出了很强的组装能力, 可用于水凝胶、有 机凝胶、纳米线、纳米管、螺旋带等纳米材料的制备, 是<smiles>O=C(Cc1ccc2ccccc2c1)N[C@@H](Cc1ccccc1)C(=O)N[C@@H](Cc1ccccc1)C(=O)O</smiles><smiles></smiles><smiles>[R]c1ccc(C[C@H](N[P+]#N)C(=O)O)cc1</smiles>

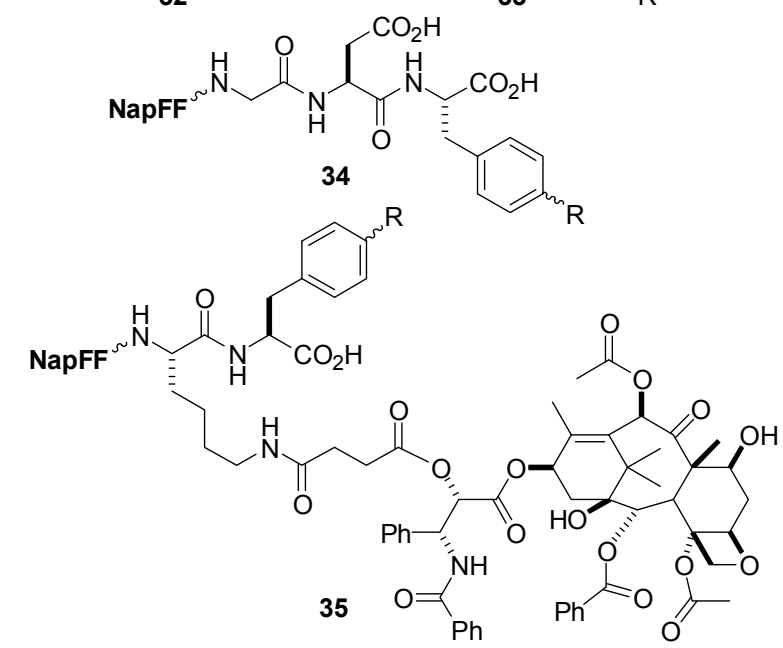<smiles>[R]SCCNC(=O)[C@H](CCC(=O)O)NC(=O)[C@H](Cc1ccc(O)cc1)NC(=O)[C@H](Cc1ccccc1)NC(=O)[C@H](Cc1ccccc1)NC(=O)CNC(=O)Cc1ccc2ccccc2c1</smiles>

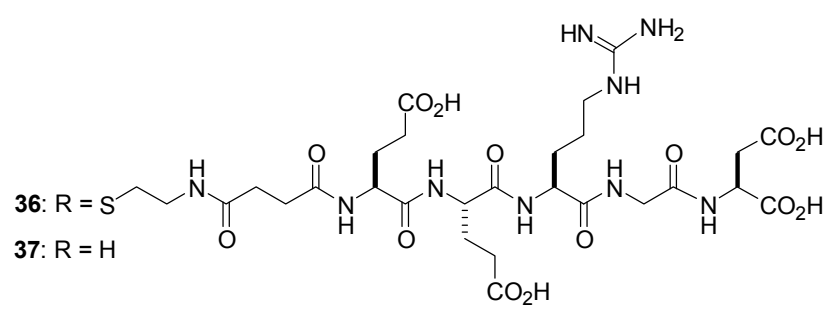

超分子自组装领域重要的构筑基元. 氨基酸自身的结构 特点, 使分子容易通过简单的化学反应引入新的功能性 基团. 对氨基酸的修饰主要是在氨基或羧基上缀合芳香 基团或疏水烷基链，使分子在氨基酸本身氢键作用，协 同 $\pi-\pi$ 作用、疏水作用等其他非共价键作用下有序排列. 不同氨基酸骨架提供的反应位点和氢键数目不等，进而 导致作用力和微观结构有所差异.

\section{2 糖类分子的自组装}

糖类化合物是自然界含量最丰富的天然产物，其结 构独特、水溶性好，骨架上多个羟基容易形成氢键促使 分子有序排列，常作为亲水基团用于超分子组装体系的 构建. 在糖分子中引入芳香基团或疏水烷基链，可促使 
分子在溶剂中达到更好的亲疏水平衡, 在多重非共价键 作用下形成稳定组装体 ${ }^{[55,56]}$.

Shinkai 等 ${ }^{[57]}$ 通过将单糖的 4,6-位羟基保护, 得到 12 个不同结构的 4,6-氧-亚苄基糖苷衍生物 38 49, 并 对它们在不同溶剂中的成凝胶性质进行研究. 发现在环 己烷、正庚烷、甲苯等有机溶剂中， $\alpha$-构型的糖苷 38、

$39 、 46 、 49$ 表现出不同的凝胶能力; 而 $\beta$-构型的糖苷，只 有 43 和 47 表现出较好的凝胶性质. 对比化合物成胶溶 剂的种类和凝胶转变温度, 发现半乳糖衍生物的凝胶性 质比甘露糖类更稳定, 也体现了单糖的结构对凝胶性质 影响很大. 光谱数据证明分子在溶剂中通过糖基团间的 氢键作用和苯环间的 $\pi-\pi$ 堆积作用有序排列形成纤维, 进而组装为凝胶.

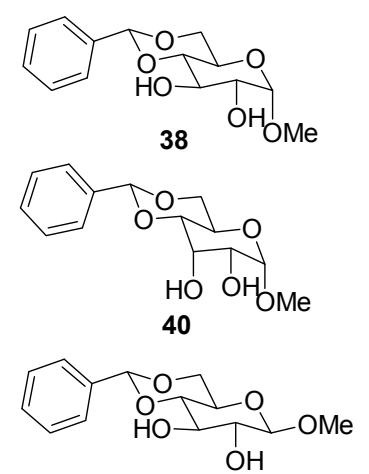

42

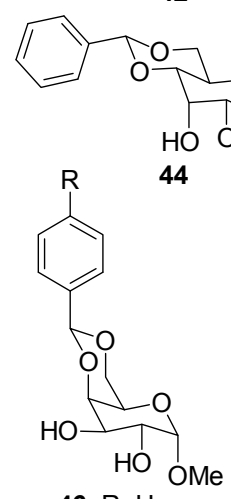

46: $\mathrm{R}=\mathrm{H}$

49: $\mathrm{R}=\mathrm{NO}_{2}$
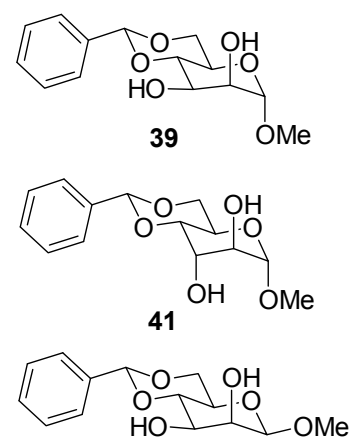

43

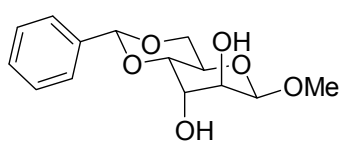

45

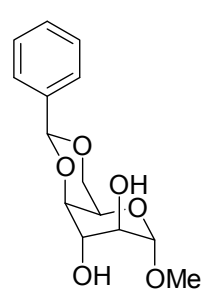

48
Sureshan 等 ${ }^{[58]}$ 以甘露醇为原料, 设计合成了其衍生 物 50 和 51, 这两种化合物在低极性烷烃溶剂和油类(食 用油、泵油、石蜡油)溶剂中均可形成高强度的凝胶. 其 中油类溶剂中形成的凝胶更加稳定，在室温下放置数月 后，凝胶的透明度、体积和形状仍维持不变. 同时，该凝 胶具有很强的自修复能力, 凝胶碎片在室温、空气中可 自愈合成整体, 基于此特性可以设计各种形貌的凝胶. 此外, 化合物 51 在石蜡油中形成的凝胶还具有很好的 光学性质, 透光强度好, 可用作软光学器件(图 4).

在自组装体系中, 刚性片段的引入通常可以有效地 促进分子在溶液中的聚集, 因此许多糖分子研究者倾向 于在亲水的糖基团上修饰共轭的芳香基团，使分子间产 生 $\pi-\pi$ 堆积作用和氢键作用，从而表现出良好的组装性
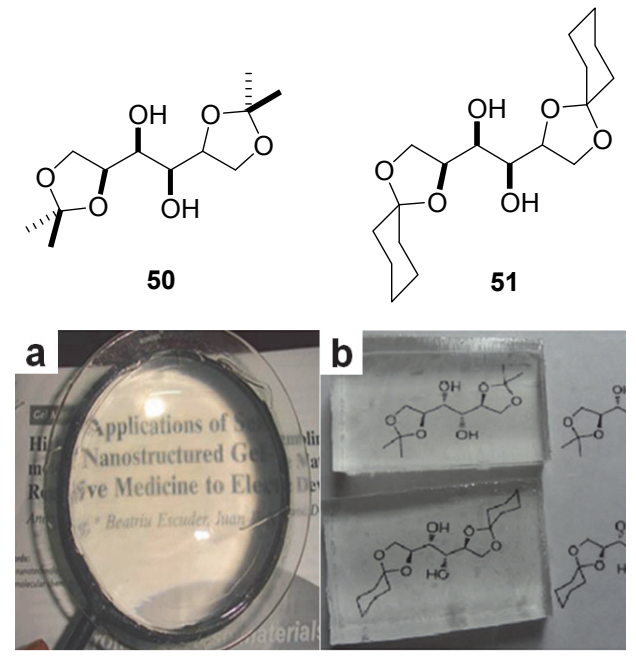

图 4 (a), (b)化合物 51 在石蜡油中形成凝胶

Figure 4 (a), (b) Gels formed by 51 in paraffin oil ${ }^{[58]}$

能 ${ }^{[59 \sim 61]}$.

偶氮苯基团因其特殊的光致异构化效应和良好的 $\pi-\pi$ 堆积作用倍受超分子化学研究者的关注. 黄建滨 等 ${ }^{[62]}$ 设计合成了以偶氮苯为连接臂、开链 $N$-甲基- $D$-葡 糖胺和丁基分别为亲、疏水端的两亲性分子 52. 分子在 水中自组装成有序的双螺旋结构，作用力主要为烷基疏 水作用力、偶氮苯 $\pi-\pi$ 堆积以及糖分子氢键作用力(图 5). 通过改变分子中烷基链长度、去掉偶氮苯基团、糖 基置换成其他亲水基团(季铵盐、羧酸钠)、调节 $\mathrm{pH}$ 、光 照、加入表面活性剂等条件, 改变了分子间的作用力和 排列方式, 进而在一定程度上实现了组装体在螺旋纤 维、胶束、囊泡间的转化. 为模拟和理解生命体系 DNA 双螺旋结构提供了一定的依据.
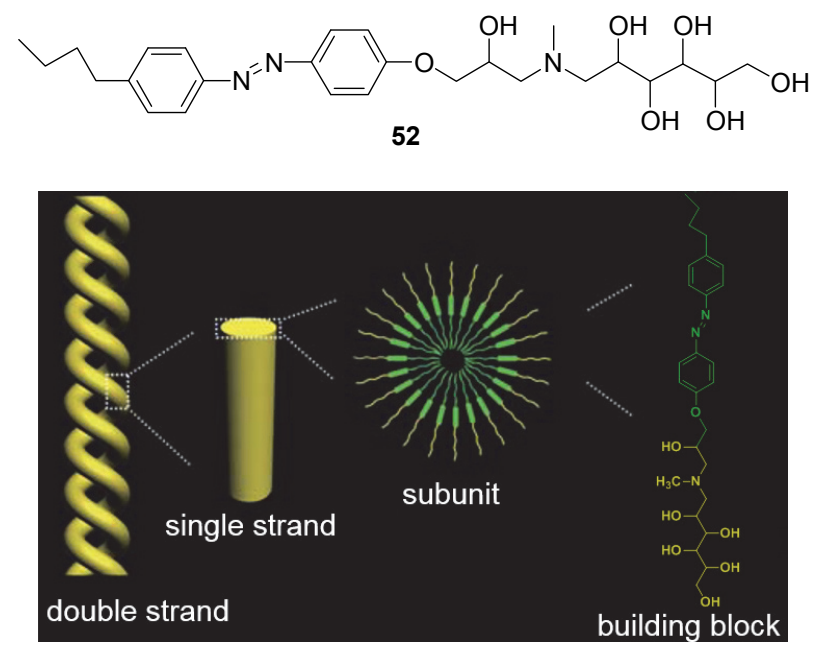

图 5 化合物 $\mathbf{5 2}$ 在水中自组装形成双螺旋示意图

Figure 5 Illustration of double-stranded helix formed by $\mathbf{5 2}$ in aqueous solution $^{[62]}$

Lee 课题组 ${ }^{[63,64]}$ 合成了一系列甘露糖分子与共轭芳 香基团缀合的棒-线型分子 $53 \sim 55$, 研究了分子结构对 组装性质及在生物应用方面的影响. 化合物 53 在水中 
自组装形成内外亲水的囊泡结构, 可包裹亲水的钲黄绿 素(calcein)染料分子, 同时囊泡外侧亲水的糖基团可以 特异性地吸附大肠杆菌菌毛 ${ }^{[63]}$. 当分子的柔性链长度 增加时, 54 自组装成尺寸较小的胶束结构; 而共轭基团 数目增加时, 55 则组装成柱状胶束. 分析三个化合物形 成组装体形貌不同的原因, 相比于 53 , 分子 54 和 55 的 构型更倾向于圆雉形, 自组装过程因几何受限容易形成 较高曲率的胶束结构. 此外, 分子 55 共轭基团的增加, 使长轴方向的 $\pi-\pi$ 作用力增强, 因此相比 54 更易形成柱 状胶束. 甘露糖基团可以选择性地识别凝集素伴刀球蛋 白(Con A), 将化合物 53 55 在水中形成的组装体加入 凝集的红血球中，可以使凝集过程得到明显的抑制. 其 中, 53 和 55 形成聚集体的抑制效果比甲基甘露糖分子 分别增加了 800 和 1000 倍, 而 54 形成聚集体的抑制效 果却增加了 1800 倍, 说明曲率较高的球形胶束比囊泡 和柱状胶束更容易抑制该凝集过程 ${ }^{[64]}$.
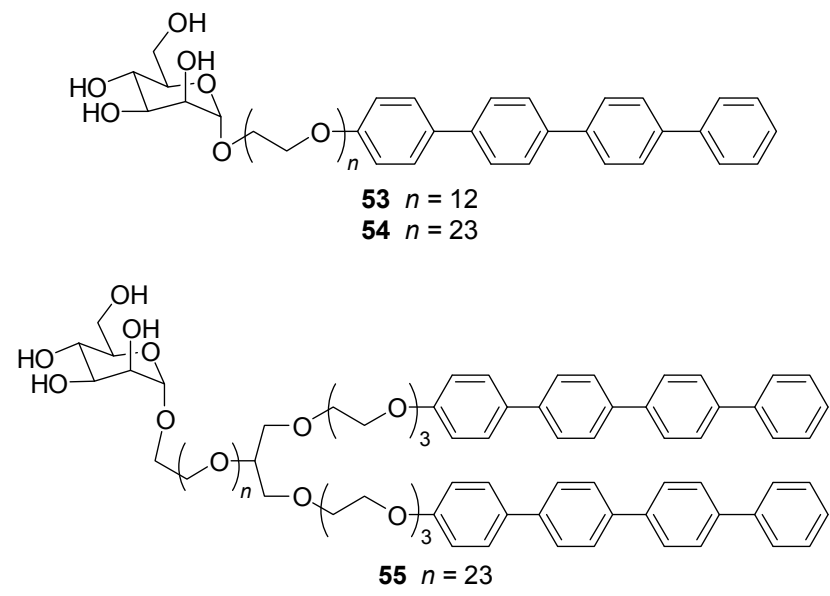

萠酰亚胺具有更大的共轭 $\pi$ 体系, 能在分子间形成 强的 $\pi-\pi$ 作用，许多学者将花酰亚胺基团修饰到糖基上， 通过自组装实现糖分子手性到超分子手性的传递 ${ }^{[65 ~ 67]}$. 魏志祥等 ${ }^{[68]}$ 在 $\beta$ - $D$-葡萄糖上修饰荘酰亚胺基团和疏水 烷基链得到两亲性分子 56, 该分子在氯仿/正辛烷体系 中形成左手螺旋的组装体, 而在四氢呋喃/水体系中形 成右手螺旋结构. 不同溶剂中组装体手性相反的原因是 两亲性分子在不同极性溶剂中排列方式不同. 非极性溶 剂中, 疏水部分在外侧排列; 而极性溶剂中, 糖基部分 在外侧, 实现了溶剂极性对超分子组装体手性的调控.

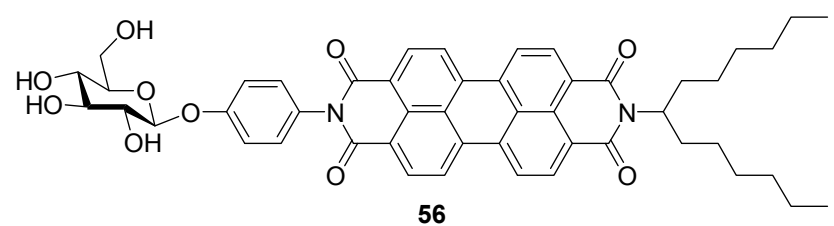

李小六等 ${ }^{[69 ~ 71]}$ 系统研究了菲酰亚胺-糖类衍生物的 手性组装性质. 他们合成了由菲酰亚胺连接的对称的 $\beta$ - $D$-乳糖二聚体 $\mathbf{5 7}$, 发现该化合物在菲酰亚胺 $\pi$ - $\pi$ 堆积
作用下, 可在 $\mathrm{H}_{2} \mathrm{O} / \mathrm{DMSO}$ 混合溶剂中自组装成右手螺 旋结构, 利用乳糖作为结合位点, 可以专一性识别花生 凝集素(PNA)(图 6) ${ }^{[72]}$.
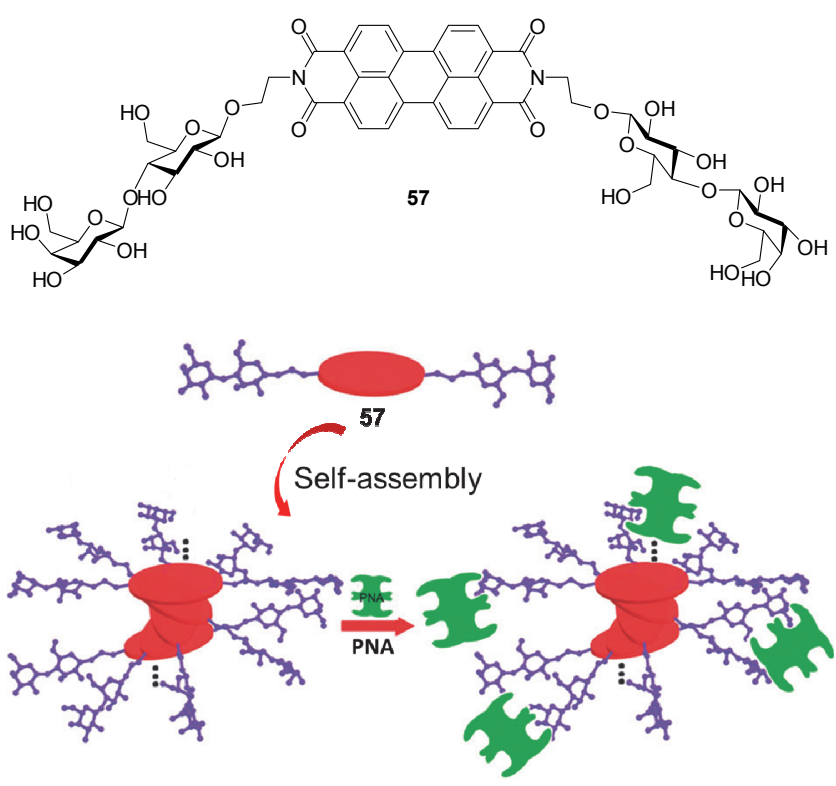

图 6 化合物 $\mathbf{5 7}$ 的自组装过程和对凝集素 PNA 的识别示意图 Figure 6 Schematic illustration of the self-assembly of $\mathbf{5 7}$ and its interaction with PNA lectin ${ }^{[72]}$

Oriol 课题组 ${ }^{[73,74]}$ 合成了一系列以三氮唑为连接臂, 二糖和烷基链分别为亲、疏水基团的两亲性分子 58 60. 这三个分子都可以在水中形成凝胶，微观形貌均 为纤维, 其中纤维二糖衍生物 59 和乳糖衍生物 60 的组 装体表现为相反的螺旋结构. 组装体的手性是分子立体 结构在超分子层面的表达，其差异可能是由于 4 位羟基 或 $\alpha / \beta-1,4$-糖苷键立体构型不同，进而导致分子在溶剂 中最优构象和排列方式不同. 通过分析分子长度和纤维 尺寸发现，该类型的两亲性分子在水体系中以疏水链朝 内、亲水糖基朝外的方式排列形成双层结构最后堆积成 纤维(图 7).

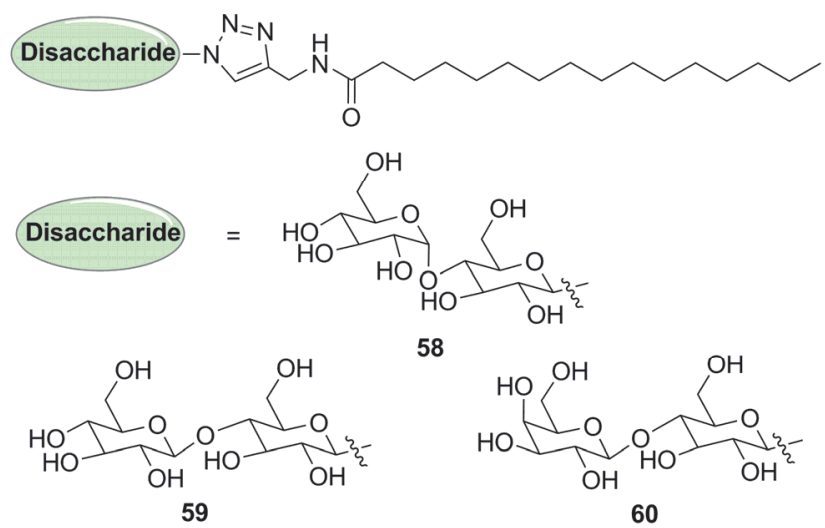

由此可见，基于糖骨架构建的超分子组装体已经被 广泛研究, 并可通过糖一蛋白间的相互作用实现对凝集 素的专一性识别. 糖分子良好的水溶性使其可作为亲水 


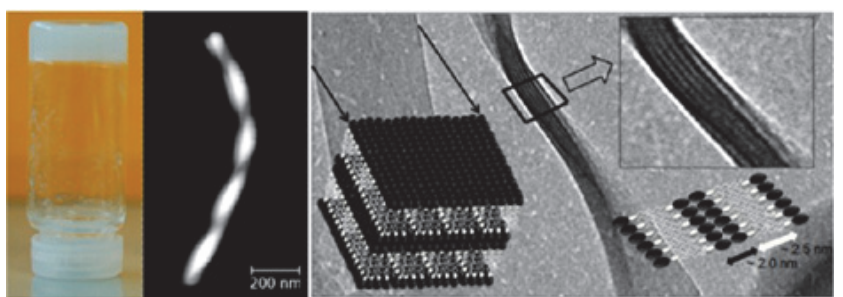

图 7 化合物 $\mathbf{5 9}$ 在水中自组装形成凝胶机理图

Figure 7 Self-assembly mechanism of hydrogel formed by $\mathbf{5 9}$ in aqueous solution ${ }^{[7]}$

基团构建两亲性分子, 疏水芳香基团或烷基链的引入促 使分子在溶剂中达到更好的亲疏水平衡，在多重作用力 下形成有序聚集体. 自组装过程中, 不同糖分子骨架上 羟基和糖苷键的构型对组装体形貌有很大的影响.

\section{3 核苷碱基化合物的自组装}

核苷广泛存在于自然界中, 是构成生物体 DNA 和 RNA 的基本单位，其碱基包括腺嘌呤 $(A)$ 、鸟嘌呤 $(\mathrm{G})$ 、 胸腺嘧啶 $(\mathrm{T})$ 、胞嘧啶 $(\mathrm{C})$ 和尿嘧啶 $(\mathrm{U})$ 等. 每个碱基分子 自身都具有许多氢键给体和受体的位点, 在核酸中, 碱 基之间可通过氢键配对形成 DNA 稳定的双螺旋结构. 碱基分子特殊的成氢键能力和 $\pi-\pi$ 作用使其成为超分子 识别和自组装化学中重要的构筑基元.

Marlow 等 ${ }^{[75]}$ 研究了一系列 $N$-乙酰基链修饰的胞嘧 啶核苷衍生物 $61 \sim 64$ 的组装性质. 四个化合物可在 $\mathrm{DMSO} / \mathrm{H}_{2} \mathrm{O}$ 或 $\mathrm{C}_{2} \mathrm{H}_{5} \mathrm{OH} / \mathrm{H}_{2} \mathrm{O}$ 混合溶剂体系中形成凝胶, 混合溶剂的比例和化合物浓度对凝胶的稳定性有一定 的影响. 通过电镜观察发现, 化合物 $\mathbf{6 2}$ 在 $\mathrm{C}_{2} \mathrm{H}_{5} \mathrm{OH} / \mathrm{H}_{2} \mathrm{O}$ 体系中形成凝胶的微观形貌为纤维网络状结构, 利用该 网孔可以对荧光示踪剂进行包裹和释放, 而且该凝胶具 有较低的细胞毒性, 为凝胶在药物传递释放方面的潜在 应用提供依据.<smiles>CCCC(=O)Nc1ccn(CC2OC(CO)C(O)C2O)c(=O)n1</smiles>

胆碱磷脂是构成细胞膜磷脂的重要成分, 探究胆碱 磷脂分子的自组装机理有助于更好地理解生物体内的 分子识别和组装过程. Grinstaff 等 ${ }^{[76]}$ 合成了一系列不同 长度烷基链修饰的尿嘧啶核酸胆碱分子 $65 \mathrm{a} \sim 65 \mathrm{~d}$ 和不 含尿嘧啶基团的分子 $66 \mathrm{a} \sim 66 \mathrm{~d}$, 并对它们组装性质进 行了研究. 实验表明, 化合物的组装性质与分子结构、 温度、溶剂以及浓度有较大关系. 当温度高于相转变温 度 $\left(T_{\mathrm{m}}\right)$ 时, $65 \mathrm{a} \sim 65 \mathrm{~d}$ 和 $66 \mathrm{a} \sim 66 \mathrm{~d}$ 均在水中形成双层的囊 泡结构, 类似于传统的磷脂双分子层; 当温度低于 $T_{\mathrm{m}}$
时, 65a 65d 自组装形成水凝胶，微观形貌表现为螺旋 纤维, 并相互缠绕成网状结构, 可用于小牛胸腺 DNA 的包裹和传递.

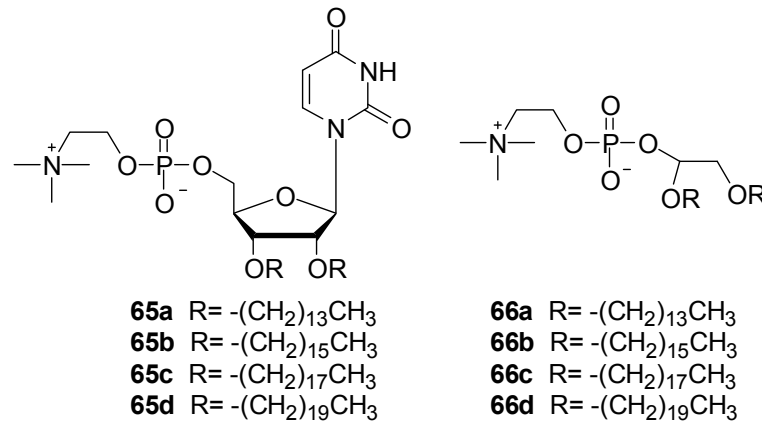

磷酸腺苷(AMP)通过 ATP 和 ADP 释放能量后产生, 对生物代谢过程有着重要的作用. $\mathrm{Xu}$ 等 ${ }^{[77]}$ 发现寡聚肽 31 (NapFF) 缀合的 AMP 衍生物 67 在水中溶解性好, 加 入碱性磷酸酶(ALP)后, 前体分子 67 水解脱去磷酸得到 凝胶因子 68 , 实现了溶液态到凝胶态的转变(图 8), 为 通过外界刺激构建新型核苷生物材料提供了依据. 此 外, 该凝胶体系中, 寡聚核苷酸 $(\mathrm{T})_{10}$ 的加入会增加分子 间相互作用，从而改变凝胶的力学性质.

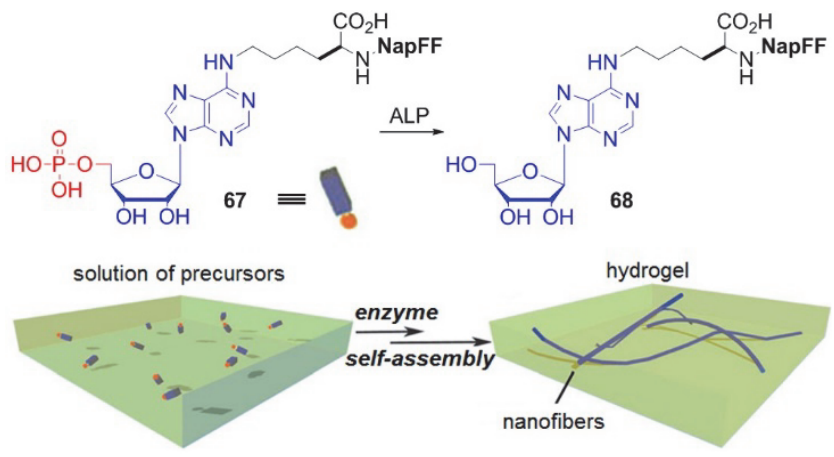

图 8 酶催化水解形成水凝胶

Figure 8 Enzyme catalyzed formation of nanofibers and hydrogels ${ }^{[77]}$

鸟嘌呤分子特有的平面芳香结构和氢键位点, 使其 能在不同条件下形成结构迥异的超分子组装体. 没有金 属离子存在时，鸟嘌呤衍生物通常在有机相中形成条带 状结构; 金属离子存在时，鸟嘌呤分子可通过氢键作用 形成 G-四聚体(G-quartet)和 G-四链体 (G-quadruplex), 这一特殊组装性质已被大量研究和报道 ${ }^{[78-80]}$. 此外, 阳 离子(如 $\mathrm{Na}^{+} 、 \mathrm{~K}^{+} 、 \mathrm{Rb}^{+} 、 \mathrm{Ag}^{+} 、 \mathrm{Au}^{+}$) 对基于鸟苷分子水 凝胶的稳定性、力学性质以及组装形貌都有较大影 响 ${ }^{[81]}$.

最近, Davis 等 ${ }^{[82}$ 发现阴离子的加入对 $\mathrm{G}$-四聚体水 凝胶的稳定性也有一定的影响. 在鸟苷分子中加入适量 $\mathrm{KB}(\mathrm{OH})_{4}$ 后，除了传统的钾离子诱导形成 $\mathrm{G}$-四聚体外， $\mathrm{B}(\mathrm{OH})_{4}{ }^{-}$还会在一定程度上促进分子的溶解，与鸟苷糖 基团上的羟基形成二聚体硼酸酯的结构, 将相邻的四聚 体通过共价键连接起来, 从而使整个体系更加稳定(图 
9). 该水凝胶可以在一定浓度 $\mathrm{KCl}$ 溶液中长时间保持稳 定，包裹阳离子染料亚甲基蓝(methylene blue)和腺嘌呤 核苷，应用在基于天然产物水凝胶的生物医学材料中.

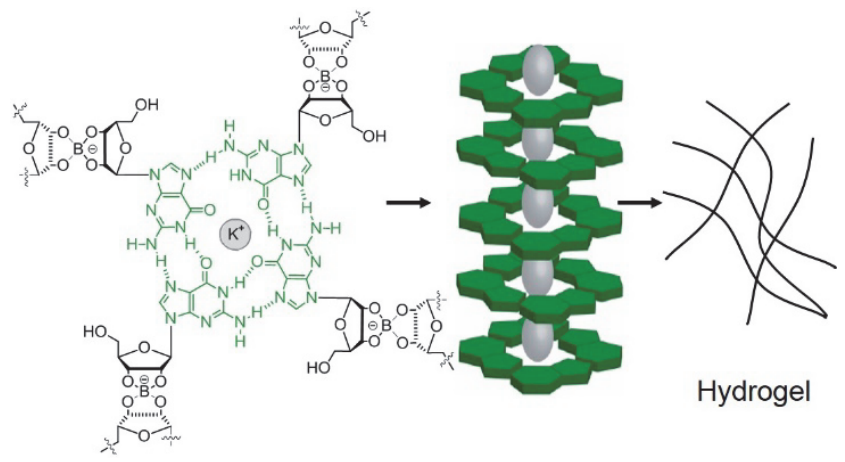

图 9 鸟苷分子在 $\mathrm{KB}(\mathrm{OH})_{4}$ 条件下形成水凝胶

Figure 9 Hydrogel formed by guanosine under $\mathrm{KB}(\mathrm{OH})_{4}$ addition ${ }^{[82]}$

因此，核苷碱基在分子间形成多重氢键作用使其有 序排列形成稳定结构, 是超分子自组装体系重要的构筑 基元, 探究其组装机理和相应组装体的应用有助于更好 地了解和模拟生命过程.

\section{4 甾体化合物的自组装}

甾体化合物广泛存在于生物体中, 具有良好生物相 容性, 与生命过程密切相关. 其中以胆固醇和胆甾酸为 骨架的衍生物在超分子组装方面的研究较多.

胆固醇分子结构独特, 具有刚性的疏水骨架和柔性 的疏水烷基侧链, 使其在溶剂中趋向于有序排列形成聚 集体，已被广泛用作有机凝胶体系的构筑基元和两亲性 分子的疏水基团 ${ }^{[15,83 ~ 85]}$. Weiss 等 ${ }^{[86]}$ 发现蒽缀合的胆固 醇衍生物 69 可在多种有机溶剂中形成凝胶. 此后, 人们 发现许多与该分子结构类似的化合物(如 70 73)都可以 在一定条件下形成凝胶 ${ }^{[87]}$, 所以把该类型分子统称为 ALS(Aromatic-Linked-Steroid)型凝胶因子. 通过对该类 分子形成凝胶的机理进行研究, 发现 ALS 型分子中芳 环部分提供的 $\pi-\pi$ 作用, 可与连接臂提供的氢键作用、 甾体提供的范德华力协同作用，使分子在溶液中有序排 列形成凝胶 ${ }^{[88}$ - 90].
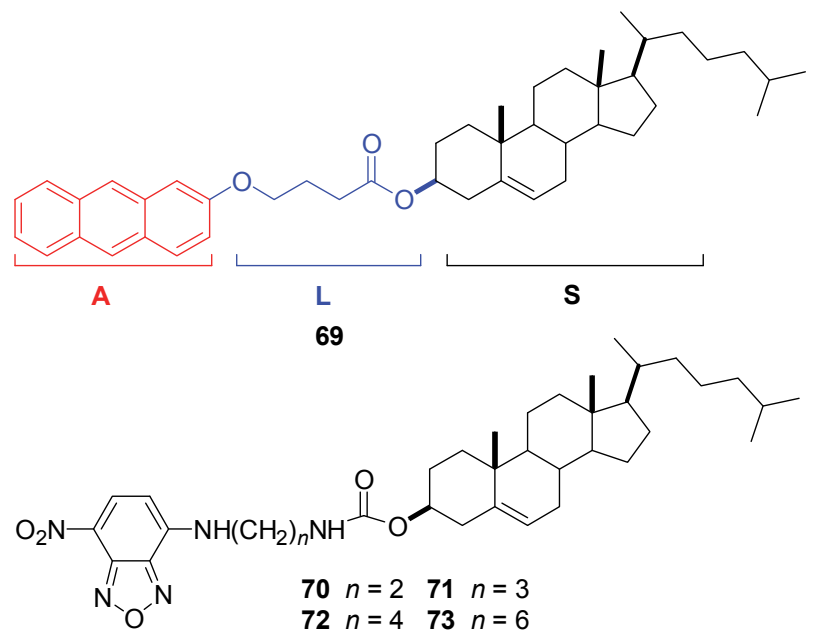

大量研究发现 $\mathrm{A}(\mathrm{LS})_{2}$ 型分子 74 76 ${ }^{[91]} 、 \mathrm{LS}_{2}$ 型分子 77 $\sim \mathbf{8 0}^{[92]}$ 、 LS 型分子 $81 \sim 84^{[93]}$ 也都具有较好的凝胶性 质，且各类分子的结构与凝胶性质有密切的关系，结构 上微小的变化(芳环类型、取代位置、连接臂长短等)都 会使凝胶性质截然不同. 已有相关学者对胆固醇凝胶因 子结构与性质的关系作了具体的研究和总结 ${ }^{[94 ~ 96]}$.

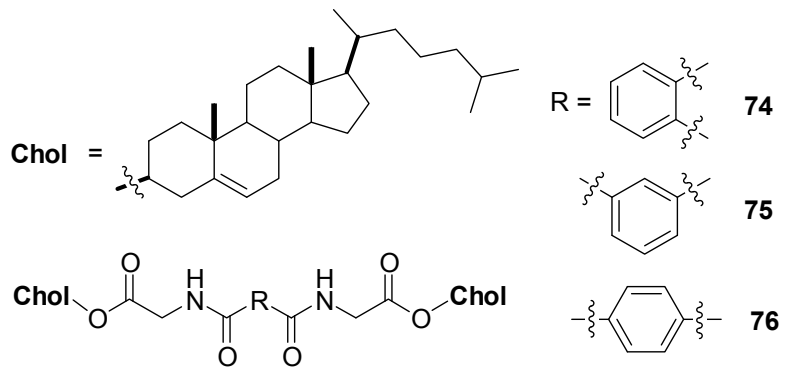

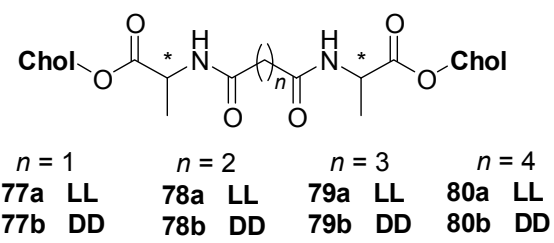<smiles>CC(C)CCCC(C)C1CCC2C3CC=C4CC(OC(=O)NCNC(=O)[C@@H](O)[C@H](O)[C@H](O)[C@H](O)CO)CCC4(C)C3CCC12C</smiles>

智能材料具有良好的感知性能，可对多种外界刺激 产生相应的变化，因而成为材料领域新的研究方向. 在 胆固醇凝胶体系中引入偶氮苯、二茂铁、二硫键等功能 性基才，可使其对光、热、 $\mathrm{pH}$ 、超声、氧化还原等多种 刺激产生响应，从而使凝胶材料功能化 ${ }^{[97 \sim 101]}$.

我们课题组 ${ }^{[102]}$ 设计合成了以二硫键连接的香豆素 胆固醇缀合物 85, 发现该分子在 $\mathrm{DMF} / \mathrm{H}_{2} \mathrm{O}$ 混合溶剂中 可形成稳定凝胶, 水含量对组装体形貌有很大影响. 光 谱研究发现，凝胶形成的作用力主要为香豆素基团的 $\pi-\pi$ 作用、连接臂的氢键作用以及胆固醇骨架的疏水作 用力. 因此，体系中水含量的改变会影响分子间的氢键 作用和疏水作用力，使分子的排列方式发生一定的改 变, 进而形成不同的组装体. 此外, 当凝胶体系中加入 小分子还原剂二硫苏糖醇(DTT)后，二硫键被还原，分 子间作用力被破坏，原有凝胶体系逐渐埋塌变成溶液， 从而实现了凝胶-溶胶转化(图 10).<smiles>CC(C)CCCC(C)C1CCC2C3CC=C4CC(OC(=O)NCCSSCCNC(=O)c5cc6ccccc6oc5=O)CCC4(C)C3CCC12C</smiles> 


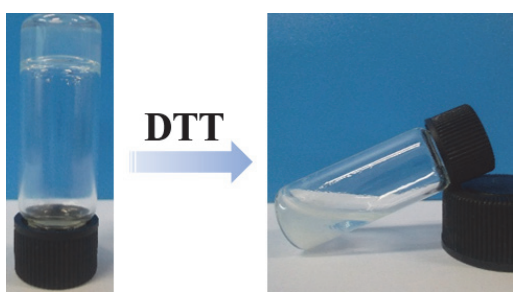

图 10 凝胶在 DTT 还原下转变为溶液

Figure 10 Redox-responsive gel-sol transition triggered by DTT ${ }^{[102]}$

Feringa 等 ${ }^{[103]}$ 设计合成了二芳基乙烯和寡聚乙二醇 修饰的胆固醇两亲性分子 86, 分子中二芳基乙烯基在 紫外光和可见光的辐照下, 可实现开环结构 86 和闭环 结构 86C 之间的可逆转化, 作为光控开关来调节组装体 的形貌. 在光照条件下, 化合物 86 在非极性苯类溶剂中 形成的凝胶可实现凝胶-溶胶的可逆转变, 而在水中形 成的薄片结构可实现与囊泡结构的相互转化, 实现了光 对组装形貌的有效调控.
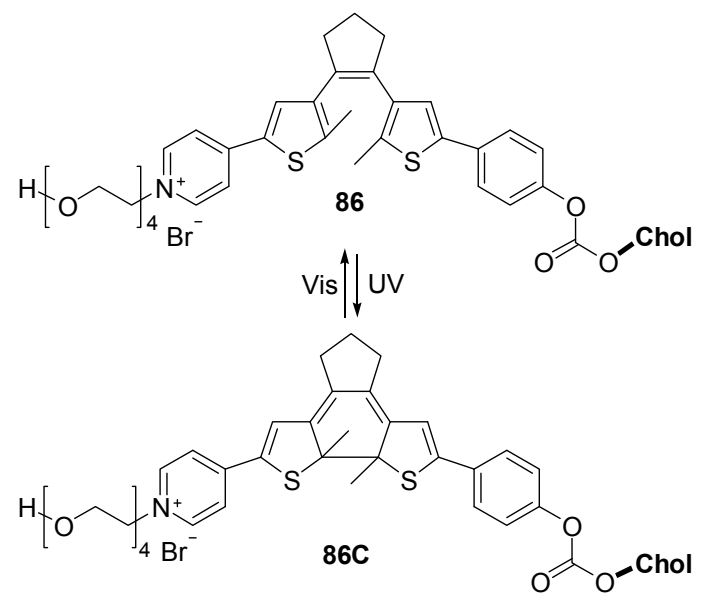

胆固醇分子除了用于有机凝胶的制备外，还可作为 疏水基团构建新的两亲性分子, 在水体系中表现出良好 的组装性质. Das 等 ${ }^{[104]}$ 合成了一系列胆固醇和氨基酸缀 合的两亲性分子 $87 \sim 89$ 和 87a $\sim 89 a$, 研究了分子结构 中亲水基团改变对组装性质的影响. 结果发现, 除 89 以 外的其他化合物都可以在水中形成稳定凝胶, 且离子型 化合物成胶能力更强. 相比于脂肪族氨基酸, 芳香基团 的引入会提供 $\pi-\pi$ 作用, 使分子成胶能力增强, 如 $88>$ $87,88 \mathrm{a}>87 \mathrm{a}$; 但芳香基团过大会破坏分子自身的亲疏 水平衡, 使 89 在水中表现为沉淀; 相反, 离子化的 $89 \mathrm{a}$ 因亲疏水平衡性好, 分子间作用力最强, 所以形成的凝 胶最稳定. 该体系水凝胶可用于细胞培养和抗菌银纳米 颗粒的制备, 并对革兰氏阳性和阴性细菌表现出良好的 杀菌效果.

柳明珠等 ${ }^{[105]}$ 合成了以胆固醇为疏水端, 药物前体 硫酸软骨素为亲水端, 二硫键为连接臂的还原响应型两 亲性分子 90. 该分子在水中自组装形成球形胶束, 亲水 性硫酸软骨素朝外, 可定向结合癌细胞表面的透明质酸 受体进而进入细胞内; 而疏水的胆固醇分子朝内, 可包

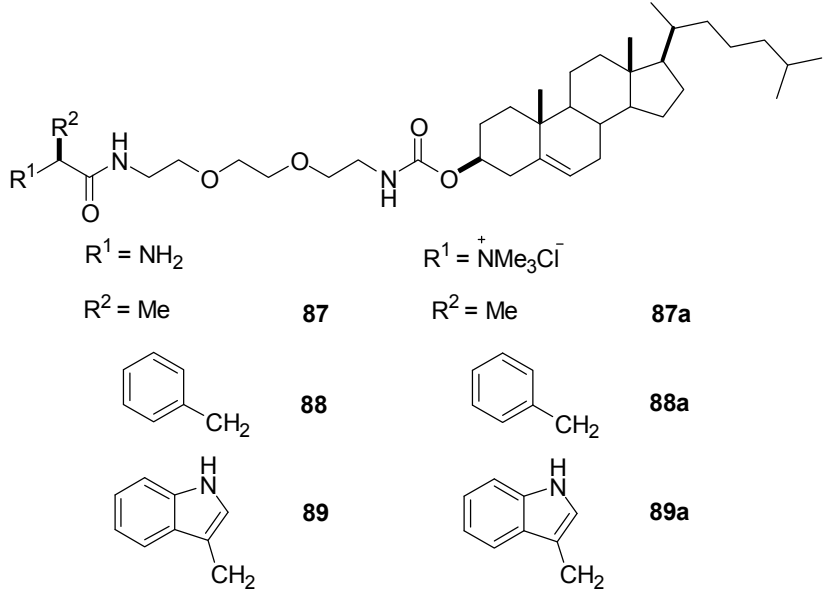

裹疏水的药物分子䚞皮素. 当用还原剂作用该药物载体 后，二硫键断开导致球形胶束破裂，进而将药物分子释 放出来, 实现对癌细胞的治疗(图 11). 通过可控的还原 响应胶束实现了疏水药物分子在靶向细胞内的传递和 释放.

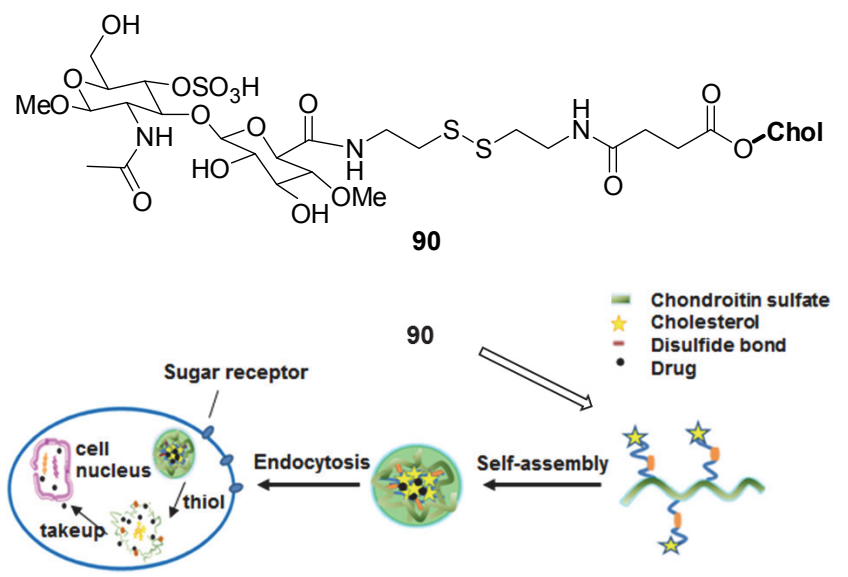

图 11 化合物 90 形成胶束并包裹药物分子在细胞内进行药物释放的 示意图

Figure 11 Scheme illustration of thiol-sensitive intracellular drug release from the micelles formed by $\mathbf{9 0}^{[105]}$

胆甾酸分子的刚性骨架呈微凹形, 分子中的羟基和 羧基指向凹面, 形成亲水的 $\alpha$ 面, 而甾体骨架和三个甲 基共同形成疏水的 $\beta$ 面，使得胆甾酸分子具有特殊的面 式两亲性. 该两亲性不同于传统的由亲水头基和疏水尾 链构成的两亲性分子, 因此, 这类分子表现出特有的自 组装行为 ${ }^{[106,107]}$. 常见的胆甾酸有胆酸 $(91)$ 、去氧胆酸 (92)和石胆酸(93), 它们之间的区别主要在于羟基数目 不同.

胆甾酸盐类化合物因其独特的亲疏水平衡作用在 水溶液中表现出很好的组装性质. Blow 等 ${ }^{[108]}$ 曾发现去 氧胆酸钠盐可在水中形成螺旋纳米线. 虽然当时人们对 螺旋线形成的机理并不是很清楚, 但后续研究证明, 胆 甾酸分子特殊的面式两亲性是其在水中形成有序聚集 


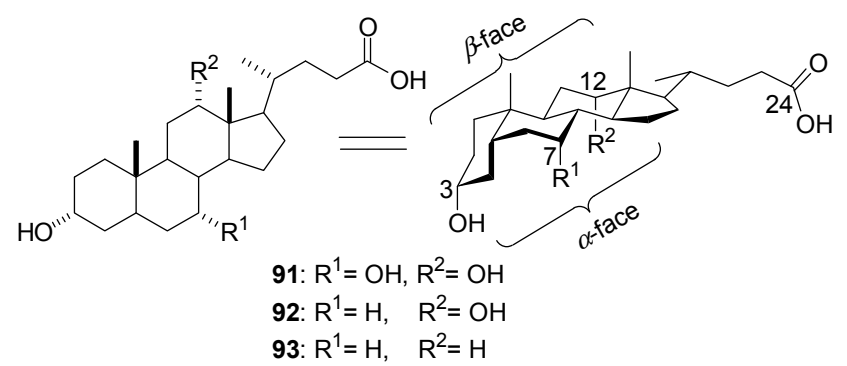

体的根本原因. 分子的疏水 $\beta$ 面相互靠近, 同时亲水的 $\alpha$ 面形成分子间氢键进而促进分子聚集, 而该组装过程 也受到温度、浓度、离子等多种外界因素的影响 ${ }^{[109 \sim 111]}$.

黄建滨等 ${ }^{[112]}$ 发现胆酸钠盐 94 在钻离子驱动下可在 分子间氢键、胆甾疏水作用、羧基和钻离子的配位作用 等多种非共价键作用下形成规则的右手螺旋纳米带(图 12). 以该胆酸钠盐-钙离子超分子体系为模板, 通过凝 胶-溶胶转换法和自模板法可制备螺旋二氧化硅无机纳 米颗粒和硫化锌螺旋纳米管. 宋爱新等 ${ }^{[113,114]}$ 也发现石 胆酸钠盐化合物在一价碱金属离子、铵根离子和二价金 属离子诱导下形成水凝胶.
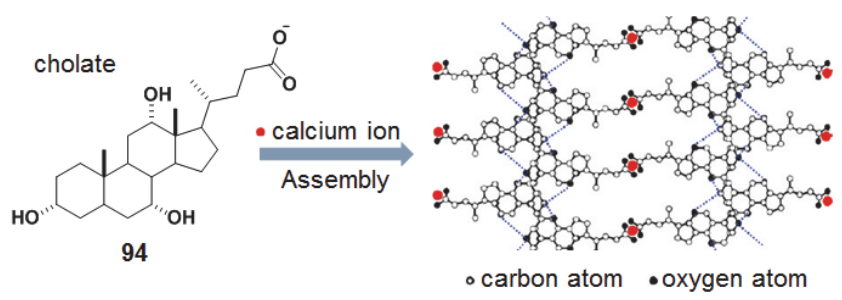

图 12 胆酸钠盐 94 在钲离子驱动下形成螺旋纳米带的机理示意图 Figure 12 Scheme illustration of helical nanoribbon from cholate 94 under the calcium ion addition ${ }^{[112]}$

胆甾酸分子中芳香基团的引入, 不仅可以增强分子 的疏水效应和 $\pi-\pi$ 作用力, 还可以赋予组装体新的光学 性质, 使其更好地应用于材料领域. Galantini 等 ${ }^{[15]}$ 将苯 丙氨酸直接缀合到胆酸 3 位, 得到两端分别裸露氨基和 羧基的两性分子 95. 该分子在中性条件下不溶, 碱性条 件下, 羧基离子化, 分子自组装形成胶束; 而酸性条件 下, 氨基被离子化, 加入电解质 $\mathrm{NaCl}$ 后分子可组装成 水凝胶, 形貌为细而长的纳米管(图 13). 由于该分子呈 楔形, 在酸性条件下正电荷的氨基排列在外侧, 羧基端 在内侧, 在苯环的 $\pi-\pi$ 堆积、胆甾骨架的疏水效应以及 分子间形成的氢键等多重作用力, 使分子有序排列形成 细长的纳米管.<smiles>C[C@H](CCC(=O)O)[C@H]1CCC2C3C(C[C@H](O)C21C)C1(C)CCC(NC(=O)C(N)Cc2ccccc2)CC1C[C@H]3O</smiles>

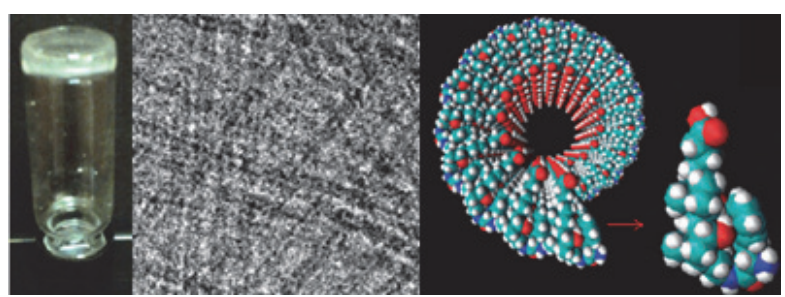

图 13 化合物 95 在酸性条件下自组装形成水凝胶

Figure 13 Hydrogel and nanotubes formed by 95 in acidic aqueous solution $^{[115]}$

除了对胆甾酸的 3 位羟基进行修饰外，在羧基上修 饰芳香基团也可以增强分子间的作用力. Maitra 等 ${ }^{[16]}$ 通 过艮基将苯丙氨酸甲酯连接在胆甾酸的 24 位羒基上, 得到 3 个不同结构的胆甾酸缀合物 $(96 \mathbf{a} \sim 96 \mathrm{c})$, 发现其 组装性质与苯丙氨酸连接在 3 位完全不同. 因羟基数量 不等, 96b 和 $96 \mathrm{c}$ 溶解性较差, 只有 $96 \mathrm{a}$ 可在部分二取代 苯类溶剂中形成凝胶. 溶剂中取代基的位置对化合物组 装性质有明显的影响, 96a 在邻二甲苯中形成凝胶, 却 在间二甲苯中析出沉淀，对二甲苯中形成溶液.<smiles>[R][R]([H])(O)[R]([H])=P</smiles>

我们课题组 ${ }^{[117]}$ 合成了葟聚对苯撑乙炔 $(\mathrm{OPE})$ 桥联 的胆甾酸二聚体 $(97 \mathbf{a} \sim 97 \mathrm{c})$, 并研究了它们在四氢呋喃/ 水混合溶剂中的自组装行为. 发现结构稍有差异的三个 化合物在溶剂中表现出截然不同的组装性质. 含较多羟 基的胆酸二聚体 97a 自组装形成囊泡结构(图 14a), 去氧 胆酸二聚体 97b 形成规整的右手螺旋带(图 14b), 而羟 基最少的石胆酸二聚体析出沉淀. 组装过程中, 97a 分 子疏水连接臂的共轭基团依靠 $\pi-\pi$ 作用和酰胺键之间的 氢键面面相对, 并使极性较大的胆酸基团暴露于溶剂中 形成囊泡; 97b 分子采取一种交错排列的方式，暴露在 外侧的去氧胆酸通过分子间氢键作用和疏水作用结合 更多胆甾基团，构成二级组装体. 这种排列方式受到去 氧胆酸骨架手性和位阻的影响, 得到螺旋结构; 而 $97 \mathrm{c}$ 分子含羟基数目较少, 疏水的石胆酸骨架在加入水后来 不及组装, 便快速聚集析出沉淀.

最近，我们 ${ }^{[18]}$ 又合成了具有聚集诱导发光性能的 胆甾酸-四苯乙烯(TPE)缀合物 98 和 99 . 分子在保留胆 甾酸原有刚性骨架和面式两亲性的基础上，又被赋予了 TPE 的聚集诱导发光特性. 研究发现, 同分异构体 98 和 99 在丙酮/水的混合溶剂中, 通过 TPE 的 $\pi-\pi$ 堆积和胆 酸亲疏水效应协同作用, 分别自组装成单分子层囊泡和 

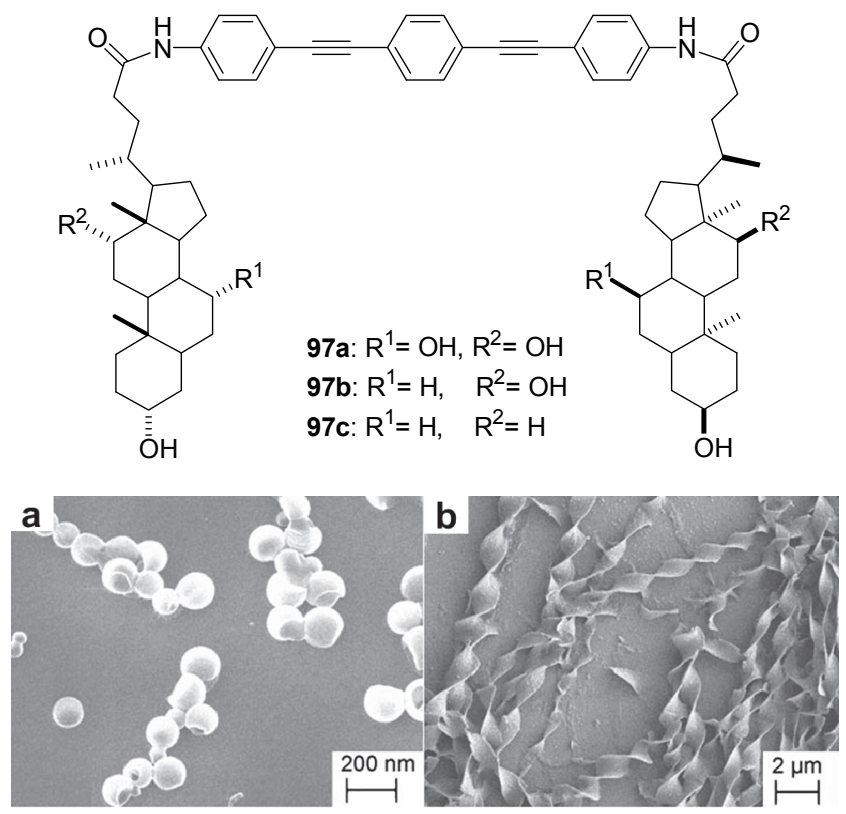

图 14 化合物 (a) 97a 和 (b) 97b 在四氢呋喃/水溶液中组装形貌

Figure 14 SEM images of supramolecular assemblies of (a) $97 \mathbf{a}$ and (b) 97b in $\mathrm{THF} / \mathrm{H}_{2} \mathrm{O}^{[117]}$

双分子层囊泡结构(图 15 所示). 这些囊泡组装过程中形 成的亲、疏水微环境可分别用于包裏亲水的硫黄素 $\mathrm{T}(\mathrm{ThT})$ 和疏水的荧光蛋白模式分子(GFP). 同时, 囊泡 的苂光特性可用于构建非共价键键合的能量转移体系.<smiles>[R]c1ccc(C(=C(c2ccccc2)c2ccccc2)c2ccc([R])cc2)cc1</smiles>

98

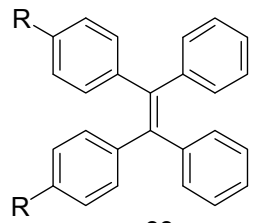

99

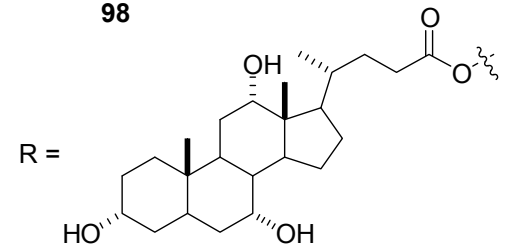

98
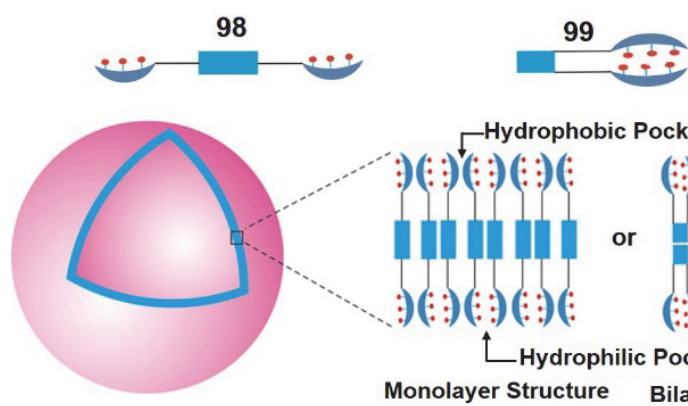

-Hydrophobic Pocket

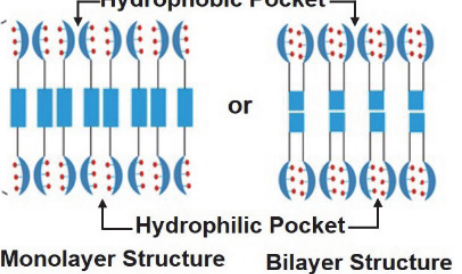

图 15 化合物 98 和 99 自组装形成囊泡和两亲性微环境示意图

Figure 15 Schematic illustration of the vesicles and amphiphilic pockets assembled from compounds $\mathbf{9 8}$ and $\mathbf{9 9}^{[118]}$

除了胆固醇和胆甾酸以外, 雌二醇衍生物也是一类 很好的凝胶因子. Sierra 等 ${ }^{[119]}$ 合成了一系列雌二醇二聚
体衍生物 100 103，研究了连接臂、17 位炔基以及羟基 对化合物在水和有机溶剂混合溶剂中凝胶性质的影响. 他们发现: (1)间位二取代的苯环连接臂比对位凝胶性质 好; (2)缩醛和二茂铁连接臂不能形成凝胶, 联二苯和 Fmoc 基团增强了 $\pi-\pi$ 作用使凝胶性质比较好; (3)17 位 炔基对凝胶性质没有影响，而羟基是形成凝胶的重要因 素. 分析凝胶形成的作用力主要为 $\pi-\pi$ 作用、氢键和雌 二醇骨架疏水作用力.

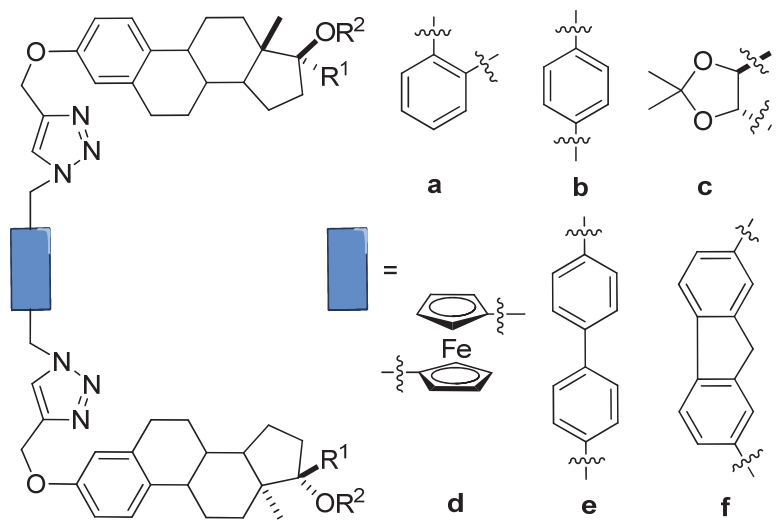

$$
\begin{aligned}
& \text { 100a-d }\left(R^{1}=-\xi=\text { TMS, } R^{2}=H\right) \quad \text { 102a-c, 102e-f }\left(R^{1}=H, R^{2}=H\right) \\
& \text { 101a-d }\left(R^{1}=-\left\{\overline{=}, R^{2}=H\right) \quad 103 a\left(R^{1}=H, R^{2}=A c\right)\right.
\end{aligned}
$$

由此可见，甾体分子独特的刚性结构和官能团决定 其在溶液中趋向于有序聚集形成组装体. 其中, 胆固醇 分子因其强烈的疏水性和范德华作用力, 多用于有机凝 胶的制备，也可作为疏水基团构建两亲性分子，研究其 在水体系的组装; 而胆甾酸分子由于其特殊的面式两亲 性，在溶剂中表现出多样化的组装行为，可用于囊泡、 纳米管、螺旋带等组装体的制备. 此外, 由于甾体化合 物来源于生物体, 其良好的生物相容性和生物活性决定 了其可以更好地应用于组织工程、生物细胞、药物传递 等生命科学领域.

\section{5 三萜化合物的自组装}

三萜化合物与甾体类化合物生物同源, 但结构略有 差异, 五环三萜化合物缺乏胆甾的柔性侧链, 但其骨架 刚性更强, 羟基所在位置和数目也不同, 这些微小差异 使二者在超分子化学中的组装行为也明显不同. 胆甾作 为超分子组装构筑基元已被广泛研究, 而三萜类化合物 的相关研究才刚刚开始.

2005 年, Bag 小组 ${ }^{[120]}$ 发现五环三萜化合物阿江榄仁 酸 104 及其衍生物在多种溶剂中表现出很好的组装性 质, 这一发现开拓了三萜化合物在超分子化学中新的研 究领域. 他们合成了一系列两亲性的阿江榄仁酸酯化合 物 105 , 发现这些酯在有机溶剂中表现出很强的凝胶能 力 $^{[121]}$. 其微观形貌为纤维网状结构, 且部分凝胶中可 观察到右手螺旋纤维, 证明了三萜骨架可作为手性凝胶 因子用于有机凝胶的制备, 将手性从分子层面传递到超 分子组装体中. 


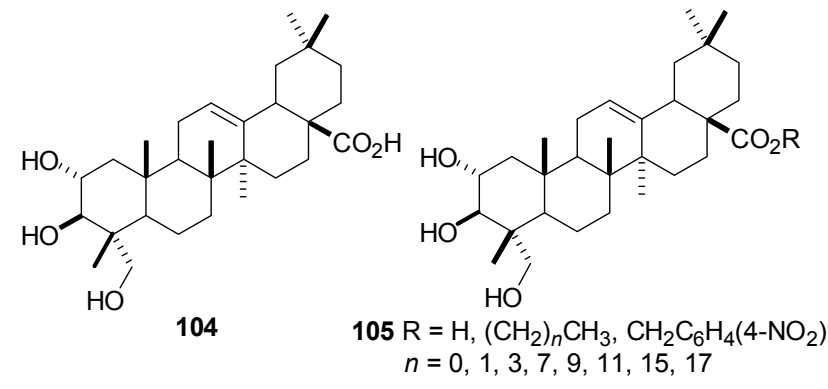

随后，他们发现未经任何修饰的白华脂酸 106 $^{[122] 、}$ 甘草次酸 $107^{[123]}$ 和齐墩果酸 $108^{[124]}$ 也在多种溶剂中表 现出很好的凝胶能力. 三个化合物结构相似, 只有羚 基、羰基、双键等位置有轻微差异, 但形成凝胶的微观 形貌却明显不同. 106 组装成纤维网络状结构, 不同溶 剂中纤维尺寸不同; 107 组装成微米花状结构, 可作为 支撑模板合成 $\mathrm{CdS}$ 纳米颗粒; 108 形成的凝胶则由不同 尺寸的纳米球组成, 可用于苂光染料分子的包裹和释 放. 在组装过程中, 三萜刚性骨架间的范德华作用以及 分子间的氢键作用是凝胶形成的主要驱动力, 但不同分 子的最优构象不同, 导致分子间形成作用力的方向和位 阻不同, 进而形成不同的组装体. 另外, 他们也合成了 阿江榄仁酸 $\mathrm{A}$ 环缩醛衍生物 $\mathbf{1 0 9}^{[125]}$, 发现这类化合物在 多种有机溶剂中形成具有纤维或囊泡结构的有机凝胶, 而且由于三萜骨架刚性较强, 所观察到纤维均呈现较好 刚性.<smiles>C=C(C)C1CCC2(O)CCC3C(CCC4C3CCC3(C)C(C)C(O)CCC43C)C12</smiles>

106

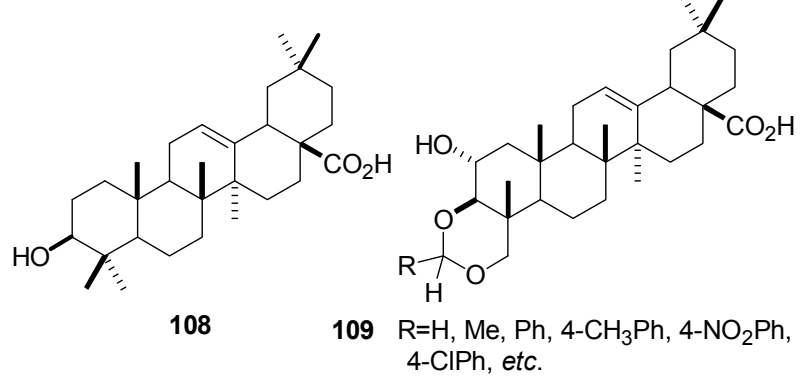

我们课题组系统研究了甘草次酸和齐墩果酸衍生 物的特有组装性质. 通过在三萜骨架上修饰一些新的功 能性基团, 如肜基、三氮唑、核苷碱基、寡聚肽、苯酰 基等, 赋予了体系新的作用力, 使缀合物的组装性质多 样化. 发现 2,3-二肜基齐墩果酸衍生物 110 可在氯代烷 烃溶剂和苯类溶剂中形成凝胶, 通过核磁、红外表征发 现分子间氢键是凝胶形成的主要驱动力. 当肟羟基或羧 基被保护后，分子间氢键作用被破坏，在相同条件下不
能形成凝胶. 此外, 该凝胶组装体能诱导非手性的甲酚 红在圆二色谱中表现出 Cotton 效应，从而证明了齐墩果 酸组装体的超分子手性 ${ }^{[126]}$.

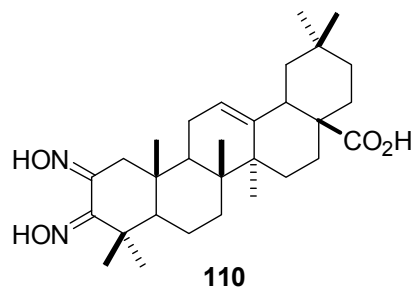

腺嘌呤缀合的齐墩果酸衍生物 111 在水的诱导下可 以凝胶四氢呋喃，通过核磁滴定等手段证明，水分子和 腺嘌呤之间形成氢键桥促进了分子的有序排列. 当齐墩 果酸骨架被环己醇替代后, 相同条件下没有任何组装行 为, 证明三萜骨架的疏水作用和腺嘌呤与水之间的氢键 作用协同促进分子的有序排列. 体系中加入互补型碱基 可破坏原有氢键桥，使凝胶体系坞塌，实现了凝胶对分 子的响应性识别 ${ }^{[127]}$.

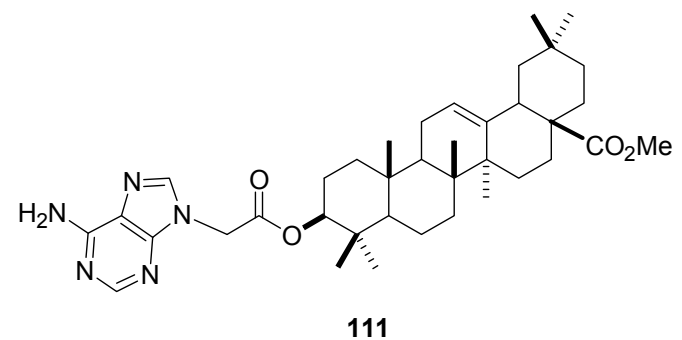

在卤代溶剂中, 尿嘧啶缀合的甘草次酸钳形分子 112 通过尿嘧啶基团间的氢键作用和三氮唑的 $\pi-\pi$ 作用 自组装形成凝胶, 可以选择性地识别能破坏氢键作用的 $\mathrm{F}^{-}$和 $\mathrm{Hg}^{2+[128]}$. 寡聚肽缀合的衍生物 113 和 114 在芳香 类溶剂中形成透明稳定的凝胶. 由于二者结构相似, 所 以凝胶性质也类似, 包括胶凝溶剂的类型和凝胶能力, 但由于结构上细微的差异, 化合物溶解性有所差别, 因 而最低凝胶浓度有所不同. 研究表明, 寡聚肽分子间的 氢键作用和三萜骨架的范德华作用力是凝胶形成的主 要驱动力. 此类型衍生物形成的凝胶可以选择性地吸附 阳离子型染料和凝胶油水体系中的有机相, 实现油水分 离 ${ }^{[29]}$.

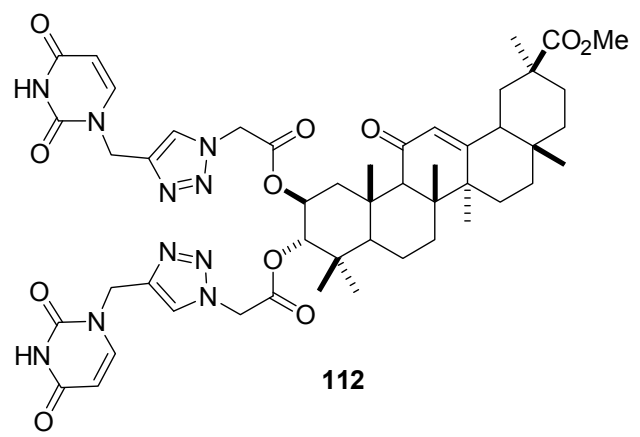




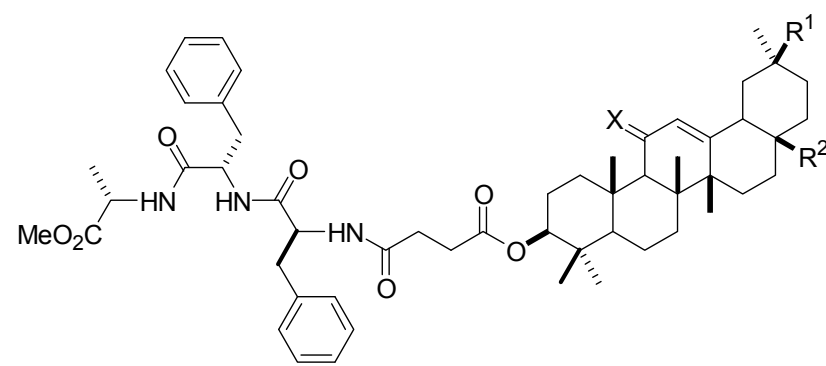

$113 \mathrm{R}^{1}=\mathrm{CO}_{2} \mathrm{Me}, \mathrm{R}^{2}=\mathrm{Me}, \mathrm{X}=\mathrm{O}$

$114 \mathrm{R}^{1}=\mathrm{Me}, \mathrm{R}^{2}=\mathrm{CO}_{2} \mathrm{Me}, \mathrm{X}=\mathrm{H}_{2}$

苯酰胺连接的甘草次酸二聚体 115 和齐墩果酸二聚 体 116 也可在多种有机溶剂中通过分子间氢键、 $\pi-\pi$ 堆 积作用以及骨架的范德华作用力形成凝胶 ${ }^{[130]}$. 由于二 者结构上的细小差异, 分子形成凝胶的溶剂种类和形貌 有所差别. 其中, 115 在 DMSO 中形成的凝胶可作为模 板原位制备和分散金纳米颗粒, 得到新的凝胶一纳米复 合材料.

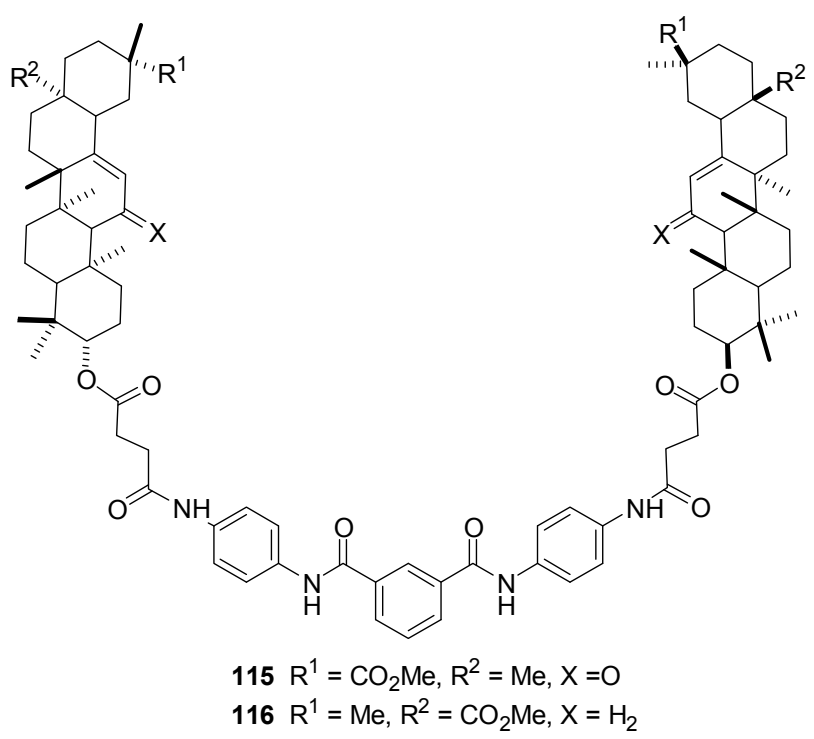

最近, 我们又在疏水的三萜骨架上修饰不同的亲水 性基团, 得到一系列新型的两亲性分子, 对它们的组装 性质进行研究. 通过将 28 位羒基碱化, 得到了两端亲水 中间疏水的甘草次酸钠盐 117 , 该分子在水中通过羧酸 钠之间的偶极作用和甘草次酸分子间的范德华作用力 形成不透明水凝胶(图 16), 可以选择性地吸附阳离子型 染料, 为凝胶材料在污水净化方面的应用提供了依 据 ${ }^{[131]}$.

此外, 我们在疏水的甘草次酸甲酯 3 位上修饰亲水 的吡啶盐基团, 构建了基于甘草次酸手性骨架的新型两 亲性分子 118. 该分子在氯仿和苯类溶剂的混合溶剂中, 通过 $\pi-\pi$ 堆积、范德华力及亲疏水作用自组装形成螺旋 纤维, 纤维相互缠绕形成三维网状结构, 进而形成透明 凝胶(图 17), 实现了三萜化合物分子手性到超分子手性 的传递和放大, 为手性组装体的构建提供了一种简单、

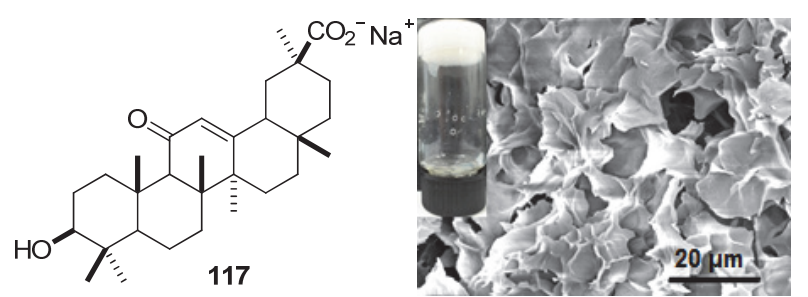

图 16 甘草次酸钠盐 117 形成水凝胶电镜图

Figure 16 SEM image of hydrogel formed by $117^{[131]}$

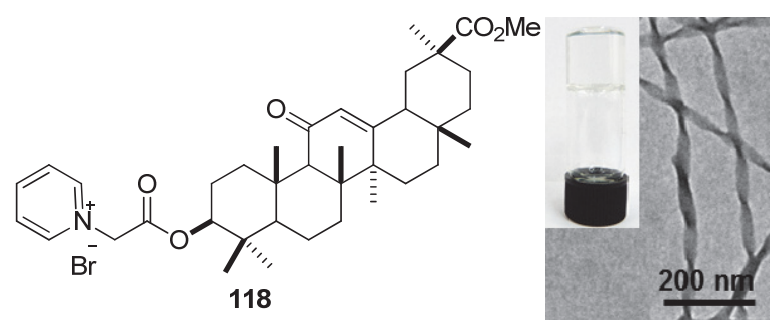

图 17 吡啶盐缀合的甘草次酸两亲性分子 118 形成凝胶及电镜图 Figure 17 TEM image of organogel formed by $\mathbf{1 1 8}^{[132]}$

有效的策略 ${ }^{[132]}$.

考虑到超分子体系中分子结构对组装性质影响较 大, 我们又合成了吡啶盐缀合的齐墩果酸两亲性分子 119, 研究了其组装行为. 发现三萜骨架的改变对分子 的组装性质影响很大. 与化合物 118 相比, 分子 119 在 相同的溶剂体系中不能形成螺旋纤维，而形成刚性的棒 状结构(图 18). 通过理论计算的方法对二者的结构进行 优化, 发现 118 中吡啶环与三萜骨架间错开一个角度, 因此分子堆积过程 $\pi-\pi$ 作用受到位阻影响, 驱使分子错 位排列形成螺旋; 而 119 的吡啶环与三萜骨架呈直线型, 容易形成有序的双层结构而非螺旋. 两亲性分子在不同 溶剂中由于亲疏溶剂作用不同而形成不同的组装体, 通 过改变溶剂极性、混合溶剂比例可以实现 119 组装体在 非极性溶剂中由球形颗粒到微米棒和极性溶剂中球形 聚集体到纳米纤维的逐步转变过程 ${ }^{[133]}$.

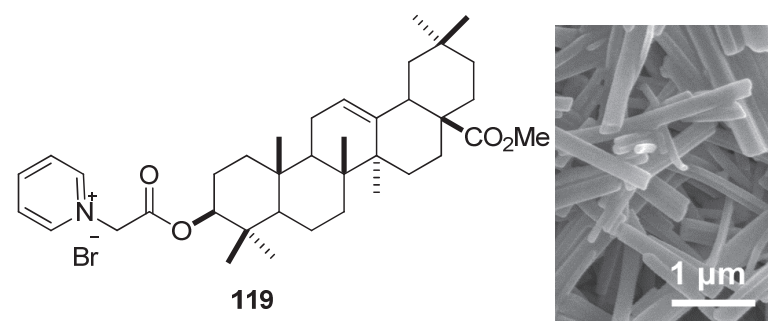

图 18 吡啶盐缀合的齐墩果酸两亲性分子 119 在氯仿/对二甲苯中形 成凝胶的电镜图

Figure 18 SEM image of organogel formed by 119 in chloroform/ $p$-xylene ${ }^{[133]}$

由于三萜骨架自身的位阻效应和强疏水作用，吡啶 盐直接缀合的两亲性分子 118 和 119 在水体系中溶解性 都较差. 在此基础上, 我们引入寡聚的聚乙二醇片段, 期望增加亲水部分作用力，获得更好的组装体. 化合物 120 在磷酸盐缓冲液中, 通过吡啶正离子-磷酸根的静 
电作用和三萜骨架疏水作用力的协同作用，自组装形成 水凝胶, 并且可用于抗癌药物阿霉素的包裹释放 ${ }^{[134]}$.

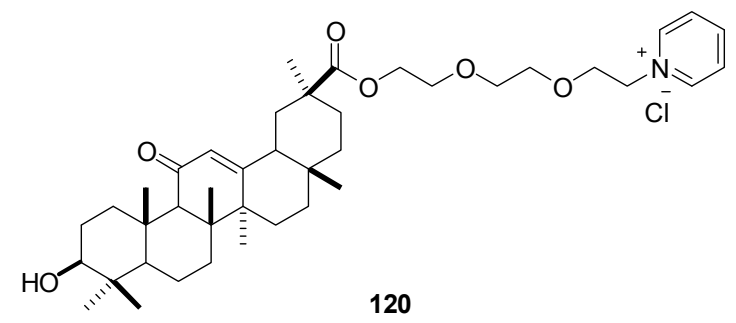

Mezzenga 等 ${ }^{[135]}$ 发现天然的甘草酸分子 121 可以在 水中自组装形成右手螺旋纤维(图 19), 这些纤维进一步 缠绕形成水凝胶. 分子中疏水的三萜骨架可与石墨烯相 互作用, 形成凝胶复合材料. 利用分子中葡萄糖醛酸的 还原性和凝胶组装体的支撑模板作用，可原位制备金纳 米颗粒, 并将其用于催化硝基苯酚到氨基苯酚的还原过 程.

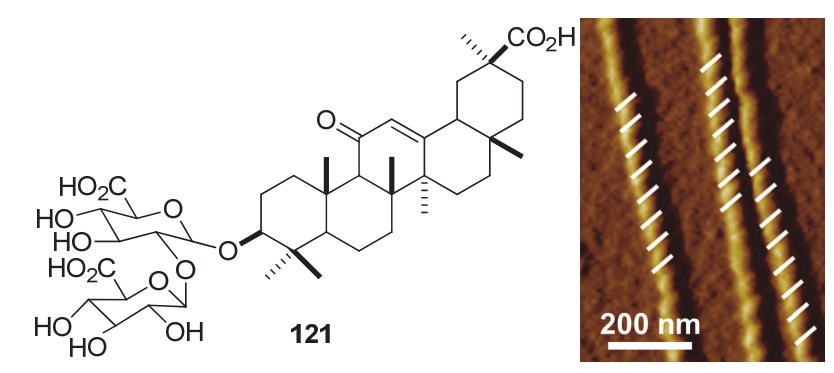

图 19 甘草酸分子 121 在水中自组装形成螺旋纤维

Figure 19 Helical nanofibers assembled by 121 in water ${ }^{[135]}$

由上可知, 三萜化合物独特的刚性骨架、手性中心 和多修饰位点, 使其成为超分子组装体的重要构筑基 元. 人们可以通过引入功能性基团和改变组装环境, 影 响成胶驱动力, 调控构筑单元的堆积方式, 从而制备具 有不同结构和性能的组装体. 由于三萜骨架强烈的疏水 效应, 目前此类化合物的组装体多在有机溶剂中形成, 随着相关研究工作的深入, 应该拓展其在水体系中的组 装, 并通过组装体将三萜本身所具有的抗炎、抗肿瘤、 杀菌等生理活性更好地发挥出来.

\section{6 香豆素化合物的自组装}

香豆素类化合物广泛存在于植物界, 具有抗菌、抗 凝血、扩冠等药理活性, 其母核结构是 $\alpha$-苯并吡喃酮, 可以提供很强的 $\pi-\pi$ 堆积作用, 同时香豆素基团还是很 强的荧光基团, 因此常被用于识别体系和主客体组装体 系 ${ }^{[136 \sim 139]}$.

Koshima 等 ${ }^{[140]}$ 合成了不同长度烷基链修饰的香豆 素的衍生物 122, 发现化合物的烷基链长度对凝胶性质 影响不大. 分子既可在低极性烷烃类溶剂正己烷、环己 烷中形成凝胶, 也可在极性较大的乙二醇、丙三醇中形 成凝胶, 不同化合物在不同溶剂中可自组装形成螺旋
带、网状纤维、空心球等形貌. 利用香豆素基团可逆的 $[2+2]$ 光聚合反应，可实现光对凝胶形貌的调控. 烷基 链最长的化合物在环己烷中自组装成螺旋纤维，随着大 于 $300 \mathrm{~nm}$ 紫外灯光照时间的延长, 螺旋纤维逐渐粘结 成块状，再经过小于 $280 \mathrm{~nm}$ 光照射后，块状又转变成海 绵状形貌.

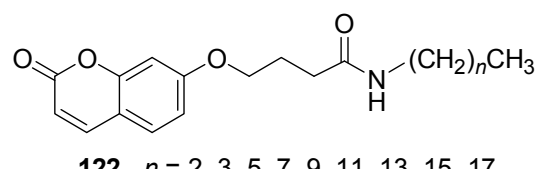

卢然等 ${ }^{[141]}$ 设计合成了 4 个不同烷基链修饰的香豆 素衍生物 $123 \sim 126$, 研究了它们在有机溶剂中的组装 性质. 发现烷基链的数目和长度对分子的凝胶性质有很 大影响, 123 和 124 在多数溶剂中溶解性好, 不能形成凝 胶; 125 仅在少数混合溶剂中表现出凝胶性质, 而 126 可 以在所测试的 14 种溶剂中形成稳定凝胶. 研究发现, 除 氢键和范德华作用在两个分子成胶过程起重要作用外, $\pi-\pi$ 作用力也在 126 组装过程发挥作用. 因此, 126 组装 形成的纤维比 125 更细长和稳定, 说明分子中烷氧链取 代基的长度也会影响分子的组装行为. 同时, 他们也研 究了紫外灯照射下香豆素衍生物 $[2+2]$ 环加成反应对凝 胶光学性质的影响.<smiles>[R]C(=O)NCCNC(=O)c1cc2ccccc2oc1=O</smiles>

123<smiles>[R]c1ccc(OCCC)cc1</smiles><smiles>[R16]#[R]c1ccc(OCC)cc1OCC</smiles><smiles>[R16]C#Cc1cc(OCC)c(OCC)c(OCC)c1</smiles>

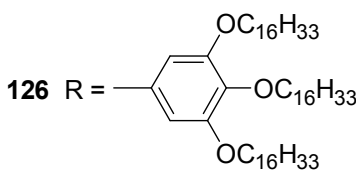

冯传良等 ${ }^{[142]}$ 发现吡啶-香豆素缀合物 $127 \sim 132$ 均 可形成稳定的水凝胶, 微观形貌为纤维网状结构. 其中, 由于吡啶取代位置和香豆素 4 位取代基的差异使得凝胶 性质稍有不同. 通过解析化合物 127 的单晶结构以及核 磁、紫外、苂光和 X-射线衍射等实验，发现该水凝胶形 成的主要驱动力为分子间氢键, 而不是 $\pi-\pi$ 作用. 考虑 到香豆素特有的苂光特性和良好的生物相容性, 研究了 化合物 130 形成水凝胶的细胞毒性以及以该水凝胶为基 质培养细胞时苂光纤维和细胞之间的作用, 为天然产物 荧光小分子在细胞成像方面的应用提供了依据.

香豆素类衍生物具有良好的光学反应活性和发光 性能，且在紫外光照条件下可发生可逆的光聚合反应， 因此, 基于此类化合物的组装体在光学材料方面有重要 的应用前景. 


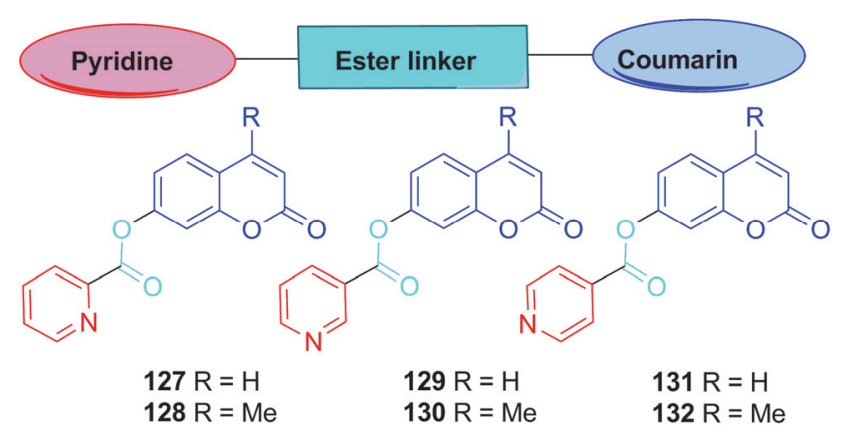

\section{7 其他天然产物的自组装}

除了上述常见天然产物外, 腰果酚、抗坏血酸、叶 酸等具有独特结构的天然产物也逐步被用于超分子自 组装体系的构建. 腰果酚(133)是腰果壳油的一种主要 成分, 由 4 种间位烷基取代的苯酚衍生物组成, 烷基为 含有 $0 \sim 3$ 个不饱和键的 C15 顺式结构. 腰果酚独特的 结构使其既具有芳香环的特征, 又具有脂肪链的柔性和 疏水性, 还可以通过酚差基进行修饰, 因此可作为超分 子组装体的构筑基元 ${ }^{[143]}$.

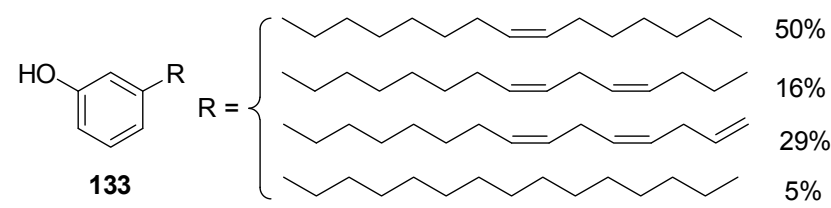

John 课题组 ${ }^{[144]}$ 将葡萄糖缀合到腰果酚上, 得到糖 脂衍生物 134 和 135 , 二者在水中都会自组装成螺旋结 构, 但混合物 134 的螺旋最终变成纳米管. 为了探究纳 米管形成过程中起主要作用的成分, 将混合物中 4 种成 分分开进行研究, 发现通过调节单烯化合物 $\mathbf{a}$ 和饱和化 合物 $\mathbf{d}$ 的比例可实现由螺旋向纳米管的逐步转变 ${ }^{[145]}$. 组装过程中, 分子在芳环 $\pi-\pi$ 作用和亲疏水作用驱动下, 使极性糖基排列在外侧, 烷基链排列在内侧而形成规整 的结构.

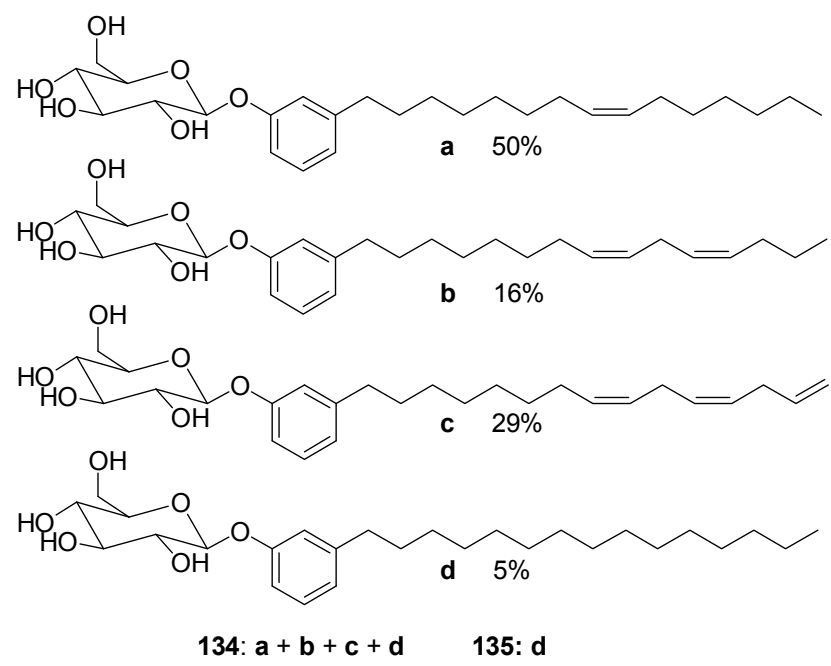

抗坏血酸是植物体内广泛存在的一类水溶性抗氧 化有机小分子，骨架上的多个羟基容易在分子间形成氢 键，促进分子有序排列形成组装体. John 等 ${ }^{[146]}$ 发现长烷 基链直接修饰的抗坏血酸酯类衍生物 $136 \mathrm{a} \sim 136 \mathrm{c}$ 可以 在水或有机溶剂中形成稳定凝胶, 该凝胶体系可以还原 氯金酸，原位制备稳定的金纳米颗粒.<smiles>CC(=O)OC[C@H](O)C1OC(=O)C(O)=C1O</smiles>

$$
\begin{array}{ll}
\text { 136a } & R=C_{7} \mathrm{H}_{15} \\
\text { 136b } & R=\mathrm{C}_{11} \mathrm{H}_{23} \\
\text { 136c } & \mathrm{R}=\mathrm{C}_{17} \mathrm{H}_{35}
\end{array}
$$

Jakob 等 ${ }^{[147]}$ 以苹果酸和酒石酸为连接臂, 通过酯化 反应将长链的脂肪酸缀合到抗坏血酸上, 得到了一系列 两亲性分子 $137 \mathrm{a} \sim 137 \mathrm{c}$ 和 $138 \mathrm{a} \sim 138 \mathrm{c}$. 它们在分子间 氢键和范德华作用力驱动下, 可在水和部分有机溶剂中 形成凝胶，分子本身具备的两亲性和抗氧化性可以使凝 胶体系很好地应用于食品和化妆品行业.
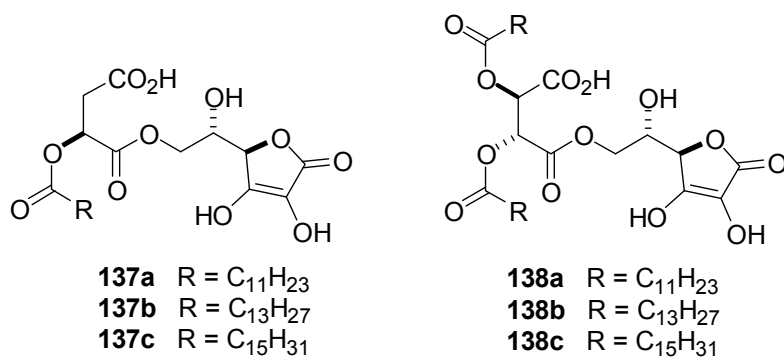

叶酸(139), 也称维生素 $\mathrm{B}_{9}$, 由喋呤、对氨基苯甲酸 和谷氨酸构成，容易在分子间形成非共价键作用. Nandi 等 ${ }^{[148]}$ 发现叶酸在 $\mathrm{DMSO} / \mathrm{H}_{2} \mathrm{O}$ 的混合溶剂中自组装形成 凝胶, 加入生物高分子壳聚糖会增强分子间的氢键作用 力, 提升凝胶体系的机械强度, 使该复合凝胶用来吸附 金属离子和染料分子. 郝爱友等 ${ }^{[149]}$ 系统研究了叶酸浓 度对该凝胶体系的影响和组装机理, 发现随着叶酸浓度 的增加, 组装体形貌逐渐由囊泡转变为纤维, 最后转变 为球形聚集体, 这一过程主要是由于叶酸分子中的喋呤 基团在不同浓度下形成氢键方式(四聚体或链状)和数目 不同而导致. 同时，他们还研究了该凝胶体系的自修复 性质和对温度、酸、碱、光照外界刺激的多重响应性质.<smiles>Nc1nc2ncc(CNc3ccc(C(=O)NC(CCC(=O)O)C(=O)O)cc3)nc2c(=O)[nH]1</smiles>

\section{3 结论与展望}

近年来，氨基酸、糖、核苷碱基、甾体、三萜、香 豆素等天然产物以其独特的立体结构和多个可修饰官 能团，在分子间能够形成非共价键作用，从而促使分子 有序排列形成聚集体，成为超分子自组装体系的重要构 
筑基元. 未经修饰或经过简单修饰的衍生物在特定条件 下可以自组装成凝胶、纤维、胶束、囊泡等结构, 并逐 渐应用于细胞培养、药物传递、染料吸附等领域. 此外, 氨基酸、糖、甾体等化合物的手性也可通过自组装传递 到超分子层面，构建螺旋带、纳米管等手性材料.

虽然天然产物在超分子自组装方面的研究已取得 一定的结果, 但目前尚存在一些需要解决的问题: (1)除 上述列举的天然产物以外, 仍有部分结构独特的天然产 物(如黄酮、生物碱)的组装性质还未开始研究; (2)深入 探究分子结构与组装性质的关系, 实现对组装过程的调 控, 制备具有特定功能的自组装体系; (3)探究自组装过 程手性选择的影响因素, 模仿生命体内的手性组装, 揭 示自然界手性来源; (4)发挥天然产物良好的相容性和生 物活性优势. 因此, 进一步深入研究基于天然产物骨架 的超分子组装特性并应用到生物医学、药物传递等生命 科学领域, 具有非常重要的意义.

\section{作者简介}

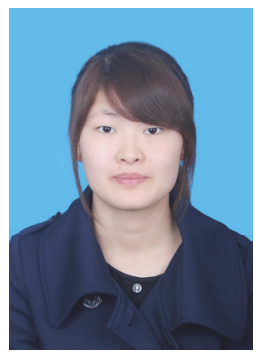

高玉霞, 清华大学化学系在读博士生. 2012 年毕业 于北京林业大学材料科学与技术学院并获得工学学士 学位. 同年9月进入清华大学化学系攻读博士研究生, 师从巨勇教授. 研究方向为基于三萜、笛体骨架的超分 子自组装及其应用研究.

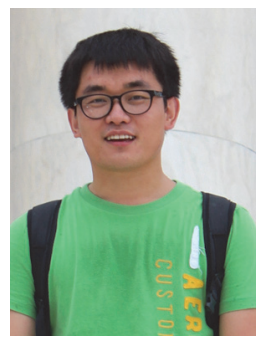

胡君, 博士, 中国科学院长春应用化学研究所副研 究员. 2006 年毕业于中国农业大学化学系, 2011 年在清 华大学化学系获理学博士学位 (导师: 巨勇教授), 随后 在美国南卡罗莱娜大学从事博士后研究. 研究方向为构 建基于超分子相互作用的功能型材料.

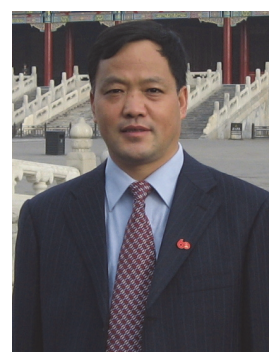

巨勇, 博士，清华大学化学系教授. 1982 年, 1992 年 分别在兰州大学获得理学学士学位和博士学位. 研究兴 趣主要包括生物活性天然产物的结构改造及其构效关 系; 生物缀合物的化学合成及其生物学功能; 新型天然 产物骨架功能分子的化学合成与性能研究.

\section{References}

[1] Whitesides, G. M.; Grzybowski, B. Science 2002, 295, 2418.

[2] Rybtchinski, B. ACS Nano 2011, 5, 6791.

[3] Prins, L. J.; Reinhoudt, D. N.; Timmerman, P. Angew. Chem., Int. Ed. 2001, 40, 2382.

[4] Zhang, L.; Wang, X.; Wang, T.; Liu, M. Small 2015, 11, 1025.

[5] Sangeetha, N. M.; Maitra, U. Chem. Soc. Rev. 2005, 34, 821.

[6] Díaz, D. D.; Kühbeck, D.; Koopmans, R. J. Chem. Soc. Rev. 2011 $40,427$.

[7] Hong, C.; Wang, H. Acta Chim. Sinica 2014, 72, 739. (洪传敏, 王 海水, 化学学报, 2014, 72, 739.)

[8] Yang, W.; Yu, S.; Chen, S.; Liu, Y.; Shao, Z.; Chen, X. Acta Chim. Sinica 2014, 72, 1164. (杨文华, 俞淑英, 陈胜, 刘也卓, 邵正中, 陈新, 化学学报, 2014, 72, 1164.)

[9] Ran, M.; Shi, D.; Dong, H.; Chen, M.; Zhao, Z. Acta Chim. Sinica 2015, 73, 1047. (再茂双, 施冬键, 董帘星, 陈明清, 赵增亮, 化学 学报, 2015, 73, 1047.)

[10] Zang, L.; Che, Y.; Moore, J. S. Acc. Chem. Res. 2008, 41, 1596.

[11] Cui, H.; Webber, M. J.; Stupp, S. I. Peptide Science 2010, 94, 1.

[12] Leininger, S.; Olenyuk, B.; Stang, P. J. Chem. Rev. 2000, 100, 853.

[13] Du, X.; Zhou, J.; Xu, B. Chem. Asian J. 2014, 9, 1446.

[14] Schnerder, H.-J.; Agrawal, P.; Yatsimirsky, A. K. Chem. Soc. Rev. 2013, 42, 6777

[15] Hosta-Rigau, L.; Zhang, Y.; Teo, B.; Postma, A.; Städler, B. Nanoscale 2013, 5, 89 .

[16] Lu, J.; Ju, Y. Chin. J. Org. Chem. 2013, 33, 469. (卢金荣，巨勇，有 机化学, 2013, 33, 469.)

[17] Ren, C.; Zhang, J.; Chen, M.; Yang, Z. Chem. Soc. Rev. 2014, 43, 7257.

[18] Kuang, Y.; Shi, J.; Li, J.; Yuan, D.; Alberti, K. A.; Xu, Q.; Xu, B. Angew. Chem., Int. Ed. 2014, 53, 8104.

[19] Duan, P.; Cao, H.; Zhang, L.; Liu, M. Soft Matter 2014, 10, 5428.

[20] Shi, J.; Gao, Y.; Yang, Z.; Xu, B. Beilstein J. Org. Chem. 2011, 7, 167.

[21] Yang, Z.; Gu, H.; Fu, D.; Gao, P.; Lam, J. K.; Xu, B. Adv. Mater. 2004, 16, 1440.

[22] Nanda, J.; Biswas, A.; Banerjee, A. Soft Matter 2013, 9, 4198.

[23] Dubey, M.; Kumar, A.; Pandey, D. S. Chem. Commun. 2014, 50, 1675.

[24] Friggeri, A.; Feringa, B. L.; van Esch, J. J. Controlled Release 2004, $97,241$.

[25] Haridas, V.; Sahu, S.; Sapala, A. R. Chem. Commun. 2012, 48, 3821.

[26] Lv, K.; Qin, L.; Wang, X.; Zhang, L.; Liu, M. Phys. Chem. Chem. Phys. 2013, 15, 20197.

[27] Wang, X.; Duan, P.; Liu, M. Chem. Commun. 2012, 48, 7501.

[28] Wang, X.; Liu, M. Chem. Eur. J. 2014, 20, 10110.

[29] Qin, L.; Duan, P.; Xie, F.; Zhang, L.; Liu, M. Chem. Commun. 2013, 49, 10823.

[30] Shen, Z.; Wang, T.; Liu, M. Chem. Commun. 2014, 50, 2096.

[31] Shen, Z.; Wang, T.; Liu, M. Langmuir 2014, 30, 10772.

[32] Liu, C.; Jin, Q.; Lv, K.; Zhang, L.; Liu, M. Chem. Commun. 2014, 50,3702 . 
[33] Suzuki, M.; Hanabusa, K. Chem. Soc. Rev. 2009, 38, 967.

[34] Suzuki, M.; Yumoto, M.; Shirai, H.; Hanabusa, K. Chem. Eur. J. 2008, 14, 2133.

[35] Song, Q.; Geng, H.; Wang, L.; Ye, L.; Zhang, A.; Shao, Z.; Feng, Z. Acta Chim. Sinica 2015, 73, 423. (宋倩颖, 耿慧敏, 王璐, 叶霖, 张爱英, 邵自强, 冯增国, 化学学报, 2015, 73, 423.)

[36] Suzuki, M.; Nakajima, Y.; Yumoto, M.; Kimura, M.; Shirai, H.; Hanabusa, K. Langmuir 2003, 19, 8622.

[37] Reches, M.; Gazit, E. Science 2003, 300, 625.

[38] Zhao, J.; Huang, R.; Qi, W.; Wang, Y.; Su, R.; He, Z. Prog. Chem. 2014, 26, 1445. (赵君, 黄仁亮, 齐崴, 王跃飞, 苏荣欣, 何志敏, 化学进展, 2014, 26, 1445.)

[39] Yan, X.; Zhu, P.; Li, J. Chem. Soc. Rev. 2010, 39, 1877.

[40] Yan, X.; Cui, Y.; He, Q.; Wang, K.; Li, J. Chem. Mater. 2008, 20, 1522.

[41] Yan, X.; He, Q.; Wang, K.; Duan, L.; Cui, Y.; Li, J. Angew. Chem., Int. Ed. 2007, 46, 2431.

[42] Yan, X.; Cui, Y.; He, Q.; Wang, K.; Li, J.; Mu, W.; Wang, B.; Ou-yang, Z. Chem. Eur. J. 2008, 14, 5974.

[43] Fleming, S.; Ulijn, R. V. Chem. Soc. Rev. 2014, 43, 8150.

[44] Jayawarna, V.; Ali, M.; Jowitt, T. A.; Miller, A. F.; Saiani, A.; Gough, J. E.; Ulijn, R. V. Adv. Mater. 2006, 18, 611.

[45] Tang, C.; Smith, A. M.; Collins, R. F.; Ulijn, R. V.; Saiani, A. Langmuir 2009, 25, 9447.

[46] Yang, Z.; Xu, K.; Wang, L.; Gu, H.; Wei, H.; Zhang, M.; Xu, B. Chem. Commun. 2005, 41, 4414.

[47] Yang, Z.; Liang, G.; Guo, Z.; Guo, Z.; Xu, B. Angew. Chem., Int. Ed. 2007, 46, 8216.

[48] Yang, Z.; Liang, G.; Wang, L.; Xu, B. J. Am. Chem. Soc. 2006, 128, 3038 .

[49] Zhang, Y.; Kuang, Y.; Gao, Y.; Xu, B. Langmuir 2011, 27, 529.

[50] Wang, H.; Yang, Z. Nanoscale 2012, 4, 5259.

[51] Gao, J.; Wang, H.; Wang, L.; Wang, J.; Kong, D.; Yang, Z. J. Am. Chem. Soc. 2009, 131, 11286.

[52] Wang, H.; Ren, C.; Song, Z.; Wang, L.; Chen. X.; Yang, Z. Nanotechnology 2010, 21, 225606.

[53] Shi, Y.; Wang, Z.; Zhang, X.; Xu, T.; Ji, S.; Ding, D.; Yang, Z.; Wang, L. Chem. Commun. 2015, 51, 15265.

[54] Ren, C.; Song, Z.; Zheng, W.; Chen, X.; Wang, L.; Kong, D.; Yang, Z. Chem. Commun. 2011, 47, 1619.

[55] Birchall, L. S.; Roy, S.; Jayawarna, V.; Hughes, M.; Irvine, E.; Okorogheye, G. T.; Saudi, N.; Santis, E. D.; Tuttle, T.; Edwards, A. A.; Ulijn, R. V. Chem. Sci. 2011, 2, 1349

[56] Chabre, Y. M.; Roy, R. Chem. Soc. Rev. 2013, 42, 4657.

[57] Gronwald, O.; Shinkai, S. Chem. Eur. J. 2001, 7, 4328.

[58] Vidyasagar, A.; Handore, K.; Sureshan, K. M. Angew. Chem., Int. Ed. 2011, 50, 8021.

[59] Wang, K. Prog. Chem. 2015, 27, 775. (王克让, 化学进展, 2015, 27, 775.)

[60] Ryu, J.-H.; Lee, E.; Lim, Y.-B.; Lee, M. J. Am. Chem. Soc. 2007, $129,4808$.

[61] Lee, D.-W.; Kim, T.; Park, I.-S.; Huang, Z.; Lee, M. J. Am. Chem. Soc. 2012, 134, 14722.

[62] Lin, Y.; Wang, A.; Qiao, Y.; Gao, C.; Drechsler, M.; Ye, J.; Yan, Y.; Huang, J. Soft Matter 2010, 6, 2031.

[63] Kim, B.-S.; Yang, W.-Y.; Ryu, J.-H.; Yoo, Y.-S.; Lee, M. Chem. Commun. 2005, 41, 2035.

[64] Kim, B.-S.; Hong, D.-J.; Bae, J.; Lee, M. J. Am. Chem. Soc. 2005, $127,16333$.

[65] Hu, J.; Kuang, W.; Deng, K.; Zou, W.; Huang, Y.; Wei, Z.; Faul, C. F. J. Adv. Funct. Mater. 2012, 22, 4149.

[66] Yang, Y.; Zhang, Y.; Wei, Z. Adv. Mater. 2013, 25, 6039

[67] Sun, K.; Xiao, C.; Liu, C.; Fu, W.; Wang, Z.; Li, Z. Langmuir 2014, 30,11040

[68] Huang, Y.; Hu, J.; Kuang, W.; Wei, Z.; Faul, C. F. J. Chem. Commun. 2011, 47, 5554.

[69] Wang, K.; An, H.; Wang, Y.; Zhang, J.; Li, X. Org. Biomol. Chem. 2013, 11, 1007.

[70] Wang, K.; An, H.; Qian, F.; Wang, Y.; Zhang, J.; Li, X. RSC Adv. 2013, 3, 23190.

[71] Wang, K.; Han, D.; Cao, G.; Li, X. Chem. Asian J. 2015, 10, 1204.

[72] Wang, K.; An, H.; Wu, L.; Zhang, J.; Li, X. Chem. Commun. 2012, $48,5644$.

[73] Clemente, M. J.; Fitremann, J.; Mauzac, M.; Serrano, J. L.; Oriol, L. Langmuir 2011, 27, 15236.
[74] Clemente, M. J.; Romero, P.; Serrano, J. L.; Fitremann, J.; Oriol, L. Chem. Mater. 2012, 24, 3847.

[75] Skilling, K. J.; Ndungu, A.; Kellam, B.; Ashford, M.; Bradshaw, T D.; Marlow, M. J. Mater. Chem. B 2014, 2, 8412.

[76] Moreau, L.; Barthélémy, P.; Maataoui, M. E.; Grinstaff, M. W. J. Am. Chem. Soc. 2004, 126, 7533.

[77] Du, X.; Li, J.; Gao, Y.; Kuang, L.; Xu, B. Chem. Commun. 2012, 48, 2098.

[78] Davis, J. T.; Spada, G. P. Chem. Soc. Rev. 2007, 36, 296.

[79] Shao, Y.; Li, C.; Zhou, X.; Chen, P.; Yang, Z.; Li, Z.; Liu, D. Acta Chim. Sinica 2015, 73, 815. (邵昱, 李闯, 周旭, 陈平, 杨忠强, 李 志波, 刘冬生, 化学学报, 2015, 73, 815.)

[80] Lin, C.; Zhai, W.; Fan, L.; Li, X. Acta Chim. Sinica 2014, 72, 709. (萑超, 翟伟, 范楼珍, 李晓宏, 化学学报, 2014, 72, 709.)

[81] Adhikari, B.; Shah, A.; Kraatz, H.-B. J. Mater. Chem. B 2014, 2, 4802.

[82] Peters, G. M.; Skala, L. P.; Plank, T. N.; Hyman, B. J.; Reddy, G. N. M.; Marsh, A.; Brown, S. P.; Davis, J. T. J. Am. Chem. Soc. 2014, $136,12596$.

[83] Wu, J.; Yi, T.; Xia, Q.; Zou, Y.; Liu, F.; Dong, J.; Shu, T.; Li, F.; Huang, C. Chem. Eur. J 2009, 15, 6234.

[84] Tu, T.; Fang, W.; Bao, X.; Li, X.; Dötz, K. H. Angew. Chem., Int. Ed. 2011, 50, 6601.

[85] Xu, F.; Wang, H.; Zhao, J.; Liu, X.; Li, D.; Chen, C.; Ji, J. Macromolecules 2013, 46, 4235.

[86] Lin, Y.-C.; Kachar, B.; Weiss, R. G. J. Am. Chem. Soc. 1989, 111, 5542 .

[87] Xu, Z.; Peng, J.; Yan, N.; Yu, H.; Zhang, S.; Liu, K.; Fang, Y. Soft Matter 2013, 9, 1091

[88] Yu, X.; Li, Y.; Yin, Y.; Yu, D. Mater. Sci. Eng., C 2012, 32, 1695.

[89] Zhou, G.; Li, Y.; Yu, X.; Yu, D.; Yin, Y. Supramol. Chem. 2012, $24,234$.

[90] Smith, M. M.; Smith, D. K. Soft Matter 2011, 7, 4856.

[91] Xue, M.; Liu, K.; Peng, J.; Zhang, Q.; Fang, Y. J. Colloid Interface Sci. 2008, 327, 94.

[92] Peng, J.; Liu, K.; Liu, J.; Zhang, Q.; Feng, X.; Fang, Y. Langmuir 2008, 24, 2992.

[93] Gao, D.; Xue, M.; Peng, J.; Liu, J.; Yan, N.; He, P.; Fang, Y. Tetrahedron 2010, 66, 2961.

[94] George, M.; Weiss, R. G. Acc. Chem. Res. 2006, 39, 489.

[95] Svobodová, H.; Noponen, V.; Kolehmainen, E.; Sievänen, E. RSC Adv. 2012, 2, 4985 .

[96] Kong, L.; Sun, T.; Zhang, F.; Xin, F.; Hao, A. Prog. Chem. 2012, 24, 790. (孔丽, 孙涛, 张峰, 辛飞飞, 郝爱友, 化学进展, 2012, 24,790 .)

[97] Murata, K.; Aoki, M.; Suzuki, T.; Harada, T.; Kawabata, H.; Komori, T.; Ohseto, F.; Ueda, K.; Shinkai, S. J. Am. Chem. Soc. 1994, 116, 6664.

[98] Sumiya, S.; Shiraishi, Y.; Hirai, T. New J. Chem. 2013, 37, 2642.

[99] Liu, J.; Yan, J.; Yuan, X.; Liu, K.; Peng, J.; Fang, Y. J. Colloid Interface Sci. 2008, 318, 397.

[100] He, P.; Liu, J.; Liu, K.; Ding, L.; Yan, J.; Gao, D.; Fang, Y. Colloids and Surfaces A: Physicochem. Eng. Aspects 2010, 362, 127.

[101] Xing, P.; Chen, H.; Bai, L.; Zhao, Y. Chem. Commun. 2015, 51, 9309.

[102] Gao, Y.; Lu, J.; Wu, J.; Hu, J.; Ju, Y. RSC Adv. 2014, 4, 63539.

[103] van Herpt, J. T.; Areephong, J.; Stuart, M. C.; Browne, W. R.; Feringa, B. L. Chem. Eur. J. 2014, 20, 1737.

[104] Dutta, S.; Kar, T.; Mandal, D.; Das, P. K. Langmuir 2013, 29, 316.

[105] Yu, C.; Gao, C.; Lü, S.; Chen, C.; Huang, Y.; Liu, M. Chem. Eng. J. 2013, 228, 290 .

[106] Mukhopadhyay, S.; Maitra, U. Current Science 2004, 87, 1666.

[107] Zhang, H.; Peng, J.; Liu, K.; Fang, Y. Prog. Chem. 2011, 23, 1591. (张荷兰, 彭军霞, 刘凯强, 房喻, 化学进展, 2011, 23, 1591.)

[108] Rich, A.; Blow, D. M. Nature 1958, 182, 423.

[109] Li, Y.; Holzwarth, J. F.; Bohne, C. Langmuir 2000, 16, 2038.

[110] Bohne, C. Langmuir 2006, 22, 9100.

[111] Jiang, L.; Wang, K.; Deng, M.; Wang, Y.; Huang, J. Langmuir 2008, 24,4600 .

[112] Qiao, Y.; Lin, Y.; Wang, Y.; Yang, Z.; Liu, J.; Zhou, J.; Yan, Y.; Huang, J. Nano Lett. 2009, 9, 4500.

[113] Wang, H.; Xu, W.; Song, S.; Feng, L.; Song, A.; Hao, J. J. Phys. Chem. B 2014, 118, 4693.

[114] Wang, H.; Song, S.; Hao, J.; Song, A. Chem. Eur. J. 2015, 21, 12194. 
[115] Travaglini, L.; D’Annibale, A.; Schillén, K.; Olsson, U.; Sennato, S.; Pavel, N. V.; Galantini, L. Chem. Commun. 2012, 48, 12011.

[116] Sajisha, V. S.; Maitra, U. RSC Adv. 2014, 4, 43167.

[117] Li, Y.; Li, G.; Wang, X.; Li, W.; Su, Z.; Zhang, Y.; Ju, Y. Chem. Eur. J. 2009, 15, 6399.

[118] Zhang, M.; Yin, X.; Tian, T.; Liang, Y.; Li, W.; Lan, Y.; Li, J.; Zhou, M.; Ju, Y.; Li, G. Chem. Commun. 2015, 51, 10210.

[119] Ramírez-López, P.; de la Torre, M. C.; Asenjo, M.; RamírezCastellanos, J.; González-Calbet, J. M.; Rodríguez-Gimeno, A.; de Arellano, C. R.; Sierra, M. A. Chem. Commun. 2011, 47, 10281.

[120] Bag, B. G.; Maity, G. C.; Pramanik, S. R. Supramol. Chem. 2005, 65,925 .

[121] Bag, B. G.; Dinda, S. K.; Dey, P. P.; Mallia, V. A.; Weiss, R. G. Langmuir 2009, 25, 8663 .

[122] Bag, B. G.; Dash, S. S. Nanoscale 2011, 3, 4564.

[123] Bag, B. G.; Majumdar, R. RSC Adv. 2012, 2, 8623.

[124] Bag, B. G.; Paul, K. Asian J. Org. Chem. 2012, 1, 150.

[125] Bag, B. G.; Majumdar, R.; Dinda, S. K.; Dey, P. P.; Maity, G. C.; Mallia, V. A.; Weiss, R. G. Langmuir 2013, 29, 1766.

[126] Hu, J.; Zhang, M.; Ju, Y. Soft Matter 2009, 5, 4971.

[127] Lu, J.; Hu, J.; Liu, C.; Gao, H.; Ju, Y. Soft Matter 2012, 8, 9576.

[128] Lu, J.; Hu, J.; Song, Y.; Ju, Y. Org. Lett. 2011, 13, 3372.

[129] Lu, J.; Gao, Y.; Wu, J.; Ju, Y. RSC Adv. 2013, 3, 23548.

[130] Lu, J.; Wu, J.; Ju, Y. New J. Chem. 2014, 38, 6050.

[131] Wu, J.; Lu, J.; Hu, J.; Gao, Y.; Ma, Q.; Ju, Y. RSC Adv. 2013, 3, 24906.

[132] Gao, Y.; Hao, J.; Wu, J.; Zhang, X.; Hu, J.; Ju, Y. Nanoscale 2015, 7,13568 .

[133] Gao, Y.; Hao, J.; Wu, J.; Zhang, X.; Hu, J.; Ju, Y. Langmuir 2016, 32,1685 .
[134] Gao, Y.; Li, Y.; Zhao, X.; Hu, J.; Ju, Y. RSC Adv. 2015, 5, 102097.

[135] Saha, A.; Adamcik, J.; Bolisetty, S.; Handschin, S.; Mezzenga, R. Angew. Chem., Int. Ed. 2015, 54, 5408.

[136] Zhang, Q.; Qu, D.; Ma, X.; Tian, H. Chem. Commun. 2013, 49, 9800 .

[137] Zhang, Q.; Yao, X.; Qu, D.; Ma, X. Chem. Commun. 2014, 50, 1567.

[138] Reddie, K. G.; Humphries, W. H.; Bain, C. P.; Payne, C. K.; Kemp, M. L.; Murthy, N. Org. Lett. 2012, 14, 680.

[139] Fan, W.; Li, M.; Hong, C.; Pan, C. Acta Chim. Sinica 2015, 73, 330 (范溦, 李敏, 洪春赝, 潘才元, 化学学报, 2015, 73, 330.)

[140] Yu, H.; Mizufune, H.; Uenaka, K.; Moritoki, T.; Koshima, H. Tetrahedron 2005, 61, 8932 .

[141] Chen, G.; Xue, P.; Lu, R.; Song, D.; Bao, C.; Xu, T.; Zhao, Y. Chem. Res. Chin. Univ. 2009, 25, 178.

[142] Ji, W.; Liu, G.; Xu, M.; Dou, X.; Feng, C. Chem. Commun. 2014, $50,15545$.

[143] Vemula, P. K.; John, G. Acc. Chem. Res. 2008, 41, 769.

[144] John, G.; Masuda, M.; Okada, Y.; Yase, K.; Shimizu, T. Adv. Mater. 2001, 13, 715.

[145] John, G.; Jung, J. H.; Minamikawa, H.; Yoshida, K.; Shimizu, T. Chem. Eur. J. 2002, 8, 5494.

[146] Vemula, P. K.; Aslam, U.; Mallia, V. A.; John, G. Chem. Mater. 2007, 19, 138.

[147] Nandi, S.; Altenbach, H.; Jakob, B.; Lange, K.; Ihizane, R.; Schneider, M. P. Org. Lett. 2011, 13, 1980.

[148] Chakraborty, P.; Roy, B.; Bairi, P.; Nandi, A. K. J. Mater. Chem. 2012, 22, 20291.

[149] Xing, P.; Chu, X.; Ma, M.; Li, S.; Hao, A. Phys. Chem. Chem. Phys. 2014, 16, 8346 .

(Cheng, F.) 